\title{
Advances and Applications of Phase Change Materials (PCMs) and PCMs-based Technologies
}

Jintao Huang, ${ }^{1,2}$ Yue Luo, ${ }^{3,4,}$ Mengman Weng, ${ }^{1}$ Jingfang Yu, ${ }^{5}$ Luyi Sun, ${ }^{6}$ Hongbo Zeng, ${ }^{7}$ Yidong Liu, ${ }^{1}$ Wei Zeng, ${ }^{8}$ Yonggang Min ${ }^{1, *}$ and Zhanhu Guo,**

\begin{abstract}
It is necessary to develop new technologies for energy storage and use of renewable energy to improve energy efficiency. Phase change materials (PCMs) are a family of energy storage materials that are among one of the most suitable materials for storing and effectively utilizing renewable thermal energy. PCM-based latent heat storage (LHS) is more advantageous than sensible energy storage because of the high storage energy density per unit volume/mass and the smaller temperature difference between storing and releasing heat. However, PCMs have low a thermal conductivity and a high degree of supercooling that are affecting their efficiency for energy storage. This review article first introduces the principle of phase change energy storage and the classification of phase change energy materials. Then, the improvement of storage methods of PCMs, and the fundamental properties that affect the application of phase change materials are discussed in detail. The applications of PCMs in various fields are also reviewed, including in solar energy utilization, waste heat recovery, construction, and civil and medical use. Finally, it summarizes the research progress of PCMs and provides an outlook for future research.
\end{abstract}

Keywords: Phase change material; Renewable energy; Thermal energy storage; Property; Application.

Received date: 10 March 2021; Accepted date: 21 April 2021.

Article type: Review article.

\section{Introduction}

The continuous growth of the population and thermal comfort requirements have led to a progressive increase in the global energy consumption rate. ${ }^{[1-3]}$ The greenhouse gas produced by the large-scale use of fossil fuels has led to the global climate's deterioration. The constant increasing in greenhouse gas emissions into the atmosphere and the high cost of fossil fuels are the primary driving forces for more efficient energy use in all areas of human activities. ${ }^{[4,5]}$

The heat storage technology that can match thermal energy supply and demand in time or space has attracted wide

\footnotetext{
${ }^{1}$ Department of Polymeric Materials and Engineering, School of

Materials and Energy, Guangdong University of Technology, Guangzhou, 510006, China.

${ }^{2}$ Key Laboratory of Polymer Processing Engineering (South China University of Technology), Ministry of Education, Guangzhou, 510640, China.

${ }^{3}$ School of Mechanical Engineering, Xiangtan University, Xiangtan, 411105, China.

${ }^{4}$ Foshan Green Intelligent Manufacturing Research Institute of Xiangtan University, Foshan, 528311, China.

5 Chemistry Research Laboratory, Department of Chemistry,

University of Oxford, 12 Mansfield Road, Oxford, OX1 3TA, UK.
}

attention from researchers and is also one of the most promising methods to improve the energy-saving efficiency of available heat sources. Thermal energy storage (TES) can be achieved by cooling, heating, melting, solidifying, vaporizing, condensing materials, and when reversing the process, energy can be obtained as heat. TES has various options that can be integrated into the energy systems comprising renewable energy resources such as solar, wind, geothermal, hydro, or even with non-renewable resources in waste heat recovery. ${ }^{[6]}$ The thermal energy can be stored by chemical as well as physical methods. ${ }^{[1]}$ In chemical TES, energy is stored and released due to reversible reactions. The chemical method of TES is classified as sorption storage ${ }^{[7,8]}$ and thermochemical energy storage ${ }^{[9]}$ Thermal energy is stored in thermochemical heat storage through decomposition reaction and then recovered in a reversible chemical reaction. The thermal cycle includes charging, storage, and discharge. ${ }^{[10]}$ Thermochemical energy storage has a very high storage density. However, various thermochemical energy storage materials are currently in the development stage, and there are few studies and applications in this area. ${ }^{[11]}$

In physical TES, the heat transfer mechanism determines the storage of heat energy. Physical energy storage can be divided into sensible heat storage (SHS) and latent heat 


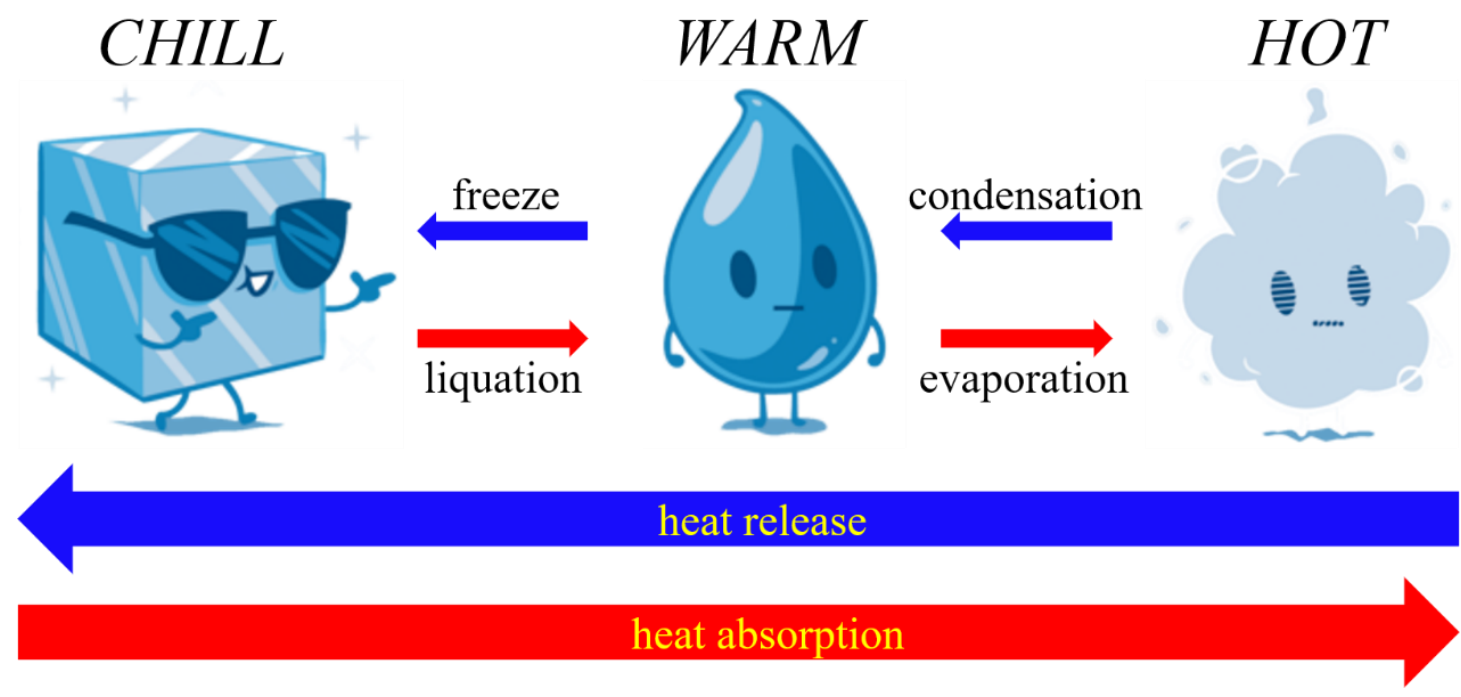

Fig. 1 Energy relations of phase change materials in different phase states.

storage (LHS). The SHS case involves storing thermal energy by raising the temperature of a solid or liquid by transfer of the heat through conduction, convection, or radiation. The principle is based on the material's change of heat capacity and temperature during the process of charging and discharging. ${ }^{[12]}$ The amount of heat stored in SHS depends on the quality, density, specific heat capacity of the storage material, and the temperature gradient between the initial and the final states. In comparison, LHS involves accumulating heat at the molecular level in a material leading to phase transformation. ${ }^{[13,14]}$

The key to latent heat storage lies in the phase transition of phase change materials (PCMs), as shown in Fig. 1. The thermodynamic state of matter (i.e., solid, liquid, and gas) changes from one to another, with the instinct to restore the original condition, that is, a physical and reversible phenomenon. ${ }^{[15,16]}$ The phase change is driven by temperature change, and the initial form of materials is responsive to the pulse of the external heat source. For example, the solid-state of a substance tends to absorb the necessary amount of thermal energy, often referred to as sensible heat, until it reaches the point where the thermally excited substance becomes liquid. This phase transition point is thermodynamically called melting point. The corresponding thermal energy is usually called latent heat, which is especially true for the enthalpy of

\footnotetext{
${ }^{6}$ Polymer Program, Institute of Materials Science and Department

of Chemical \& Biomolecular Engineering, University of Connecticut, Storrs, CT 06269, United States

${ }^{7}$ Department of Chemical and Materials Engineering, University of Alberta, T6G 1 H9 Edmonton, Canada

8 Institute of Chemical Engineering, Guangdong Academy of

Sciences, Guangzhou, 510665, China

${ }^{9}$ Integrated Composites Laboratory (ICL), Department of Chemical and Biomolecular Engineering, University of Tennessee, Knoxville, TN 37996, USA

*Email: meluoyue@163.com (Y. Luo); yong686@126.com (Y. Min); zguo10@utk.edu (Z.Guo)
}

melting or crystallization. The most important thing is that the melting enthalpy occurs at a thermodynamically constant temperature throughout the transformation process and further depends on the melting temperature, chemical configuration, and crystallographic arrangement of the PCM that is not considered. ${ }^{[17]}$

The amount of heat stored in LHS depends upon the mass and melting latent heat of the PCMs. The energy storage for the PCMs comprises the sensible and latent heat equations as the temperature rise of the material leads to the phase transformation. The working mechanism of PCMs involves absorption of a considerable amount of heat energy when reaching the phase change temperature. This energy is then released during the cooling process. LHS relies on the phase change material to absorb or release heat because it undergoes a solid to solid, solid to liquid, or liquid to gas phase transition and vice versa. During this phase transition process, the heat absorbed is called the crystallization or melting latent heat, depending upon the material's phase under consideration. ${ }^{[18]}$

Among different TES types, in many cases, latent heat storage (LHS) is preferable because LHS has the most flexible operating temperature range. The advantage of using latent heat is that the energy storage density is about 10 times that of latent heat storage technology, smaller system size, lightweight per unit storage capacity, and higher round-trip efficiency ${ }^{[19,20]}$ Therefore, PCMs have been widely applied in building energy saving, solar power generation systems, and waste heat recovery, thermal management systems, and so on.

\section{Classification, storage, and properties of phase change materials}

\subsection{Classification of phase change media}

According to the phase transition temperature, PCM can be divided into three categories: (i) low-temperature PCM phase transition temperature is below $15^{\circ} \mathrm{C}$, usually used in air conditioning applications and food industry; (ii) the most popular medium temperature PCM has a phase transition 


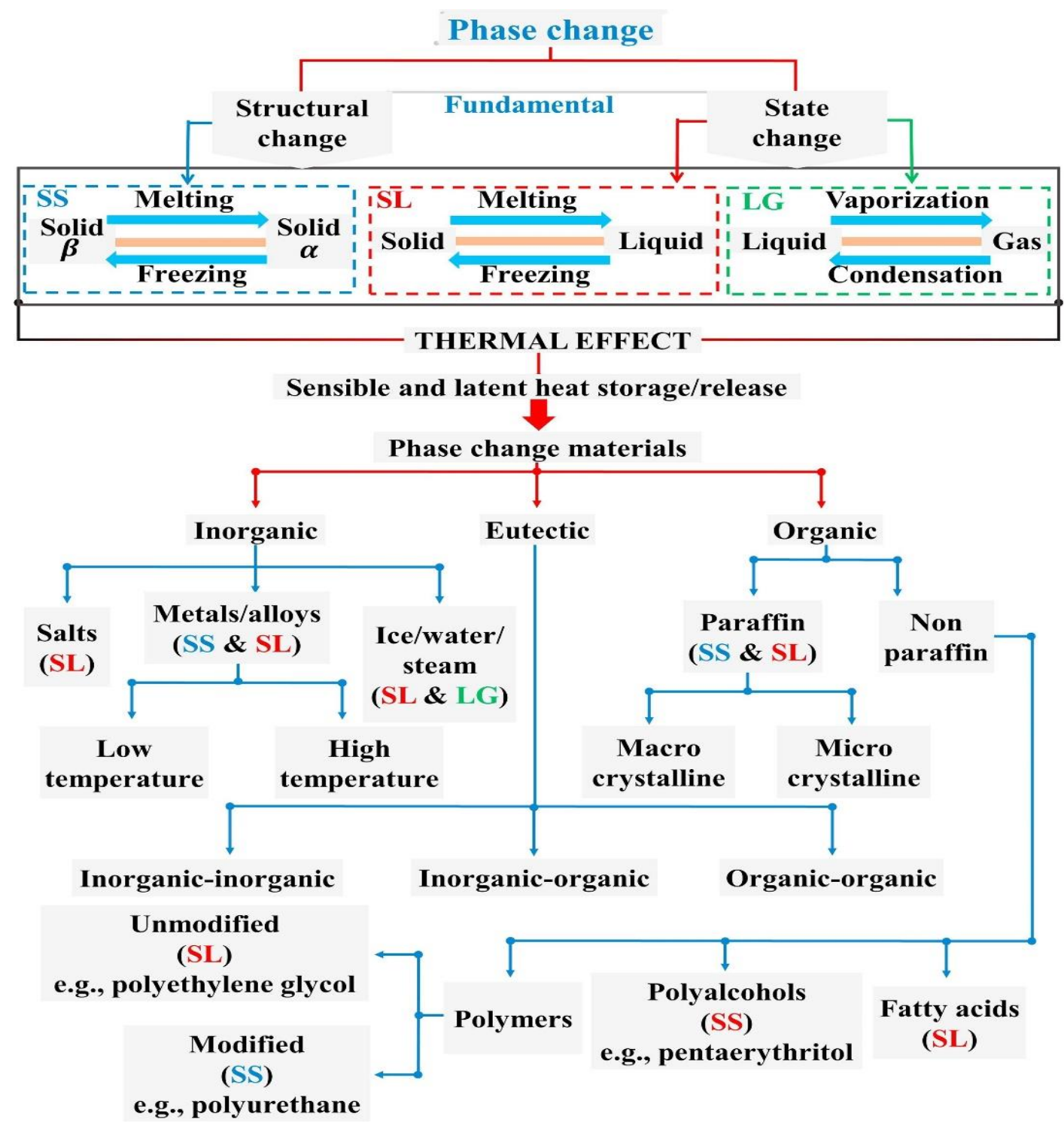

Fig. 2 Phase change dependent classification. (Reproduced with the permission form [17], Copyright, 2019 Elsevier Ltd.)

temperature between $15-90{ }^{\circ} \mathrm{C}$ and has solar energy, medical, textile, electronic and energy-saving applications in architectural design; (iii) high-temperature PCM with a phase transition higher than $90{ }^{\circ} \mathrm{C}$ is mainly used in industry and aerospace applications. ${ }^{[21]}$

PCM can also be classified by its phase change mode:[22] solid-solid, solid-liquid, liquid-gas, and solid-gas phase change materials. Solid-solid phase change materials have the advantages of no liquid production, small volume change, no corrosion, and long service life. However, they have disadvantages such as low latent heat of phase change and high phase change temperature. ${ }^{[23]}$ Liquid-gas phase change materials and solid-gas phase change materials have high latent heat of phase change. However, because they have the disadvantage of large volume changes, it is not commercially feasible for large-scale TES. Solid-liquid phase change materials have received widespread attention because of their huge latent heat of phase change and small volume change. However, it is easy to leak when heated.
In the research on PCM, different kinds of materials, including organic and inorganic compounds and eutectic PCM, can be used in TES, ${ }^{[17]}$ as shown in Fig. 2. Organic PCMs used in TES include paraffin, fatty acids, alcohols, and various compounds. Inorganic PCMs are further subdivided into salts, salt hydrates, and metals. Eutectic PCMs are designed with unique engineering materials with required thermophysical properties using a mixture of ingredients (molar fraction) at the eutectic point. ${ }^{[24,25]}$

\subsubsection{Organic PCMs}

This section introduces organic PCMs, include paraffin waxes, poly(ethylene glycol)s, fatty acids and fatty acid derivatives, and polyalcohols and polyalcohol derivatives.

\subsubsection{Paraffin waxes}

Natural paraffin (saturated hydrocarbon with molecular formula $\mathrm{C}_{n} \mathrm{H}_{2 n+2}$ ) is a by-product produced in crude oil refining and has high practical application value. Paraffin has 
a large scale, relatively low price, high fusion heat, and moderate TES density. It also has a high latent heat storage capacity in a narrow temperature range and is considered nontoxic and ecologically harmless. These paraffin characteristics meet the requirements of PCM for energy storage. Thus it is a widely used solid-liquid PCM. However, due to the low thermal conductivity, a larger surface area is required, which reduces the heating rate during the melting and solidification cycle. ${ }^{[26,27]}$

The latent heat of paraffin wax is based on molar mass, and their various phase transition temperatures can be flexibly selected for specific latent heat TES applications. They are economically feasible, and repeated cycles during the solidliquid transition will not cause phase separation. Generally, the longer the average length of the hydrocarbon chain, the higher the melting temperature and heat of fusion. ${ }^{[28]}$ Besides, PCM characteristics can also be designed by mixing physically different paraffin. Himran et al. ${ }^{[29]}$ first systematically studied paraffin's thermophysical properties as a latent heat storage material. In recent years, many researchers have explored the paraffin wax's thermal properties during melting and solidification. ${ }^{[17,30]}$ Literature data show that after 1000-2000 cycles, commercial-grade paraffin and other pure paraffin have stable performance and good thermal reliability. Paraffin waxes are safe, non-reactive, and compatible with metal containers because they do not promote corrosion. However, it should be careful when using plastic containers because the paraffin's chemical similarity and affinity can cause the penetration and softening of specific polymers (especially polyolefins). ${ }^{[28]}$

\subsubsection{Poly(ethylene glycol)s (PEGs)}

PEG is $\mathrm{OH}$-terminated polyethylene oxide. It is an essential semi-crystalline polymer with a repeating unit of $-\mathrm{CH}_{2}-\mathrm{CH}_{2}$ O-. It is used in water-based coatings, textile fiber, paper coatings, packaging materials, and a solubilizer for drugs. TES involves a relatively new PEG application area used as PCM because it has a high heat of fusion attributed to high crystallinity. ${ }^{[31]}$ The molecular weight is a vital issue when PEG is used as a TES material. The melting point of PEG is dependent on the molecular weight and may vary from ca. 4 to $70{ }^{\circ} \mathrm{C}$, with the heat of fusion in the range of $117-174 \mathrm{~J} / \mathrm{g}$. An increase in the molecular weight of PEG causes an increase in the melting temperature and the heat of phase transition. The molecular weight also influences the degree of crystallinity, ranging from $83.8 \%$ to $96.4 \% .{ }^{[32]}$ However, PEG has good melt flowability, and all of these methods have their limitations: the risk of deformation failure and leakage during the phase change in practical applications.

Therefore, PEG is a typical organic PCM suitable for photo-thermal conversion and thermal energy storage. It has a high phase change enthalpy, an easily regulated phase change temperature, environmentally friendly, chemically stable, and so on. ${ }^{[33-37]}$

\subsubsection{Fatty acids and fatty acid derivatives}

Fatty acid is a standard PCM with many superior properties, including suitable melting temperature range, high heat capacity, complete melting, little or no supercooling during phase change, low vapor pressure, non-toxic, non-corrosive to metal containers, good thermal stability, low cost, noncombustibility, and small volume changes. ${ }^{[38,39]}$ The fatty acids commonly used to make PCM mainly include capric acid, lauric acid, myristic acid, palmitic acid, stearic acid, oleic acid. Researchers also discovered that two or more fatty acids could be mixed to form a eutectic mixture with a lower phase transition temperature. It was also found that fatty acid esters can be synthesized by esterification, and fatty acid composite PCM can also be prepared in different ways. These fatty acid derivatives enrich the applications of fatty acids.

Phase change temperature and latent heat are two basic parameters of phase change materials (PCM). The phase transition temperature and latent heat of saturated fatty acids increase with carbon chain length. Also, the application of fatty acid as PCM is affected by other physical and thermal properties of fatty acids, such as density, specific heat, and thermal conductivity.

Sari et al. ${ }^{[40,41]}$ used expanded perlite (EP) as a support material and capric acid (CA) and lauric acid (LA) as PCM to prepare $\mathrm{CA} / \mathrm{EP}$ and $\mathrm{LA} / \mathrm{EP}$ composite PCM. It is found that LA is well compatible with EP, and EP has a maximum absorption rate of $55 \%$ by weight on $\mathrm{CA}$ and $60 \%$ by weight on LA. After 1000 thermal cycles, the phase transition temperature and phase transition enthalpy of LA/EP and $\mathrm{CA} / \mathrm{EP}$ hardly change.

\subsubsection{Polyalcohols and polyalcohol derivatives}

Polyols are compounds with multiple hydroxyl functional groups. The polyol has undergone a first-order phase transition with zero change in Gibbs energy. ${ }^{[42]}$ The volume change of polyols is minimal, and there is no segregation or phase separation; more importantly, it has high enthalpy and lowtemperature phase change. Therefore, they can be used as perspective phase change materials for thermal energy storage. Polyols or so-called organic molecular crystals exhibit a high solid-solid phase change enthalpy. This behavior of polyol has attracted the attention of some researchers to study its performance as PCM for heat storage. ${ }^{[2-45]}$ However, the thermal conductivity of organic molecular crystals is very low. For the application of PCM, it is necessary to enhance the thermal conductivity to meet the application requirements.

\subsubsection{Inorganic PCMs \\ 2.1.2.1 Salt hydrates}

Salt hydrates are an essential class of medium and lowtemperature PCM for heat storage, with the melting point ranges from ca. $5^{\circ} \mathrm{C}$ to $100{ }^{\circ} \mathrm{C}$. The phase change process of salt hydrates means that hydrated salt desorbs crystal water and absorbs heat during heating. Inorganic salt and water recombine to form hydrated salt and release heat during 
cooling. Compared with organic PCM, hydrated salt is usually neutral. It has a fixed melting point, higher heat of solution, higher energy storage density, small volume change during phase change, and relatively higher thermal conductivity. Therefore, hydrated salts have received widespread attention. Common hydrated salt phase change materials include alkali metal, alkaline earth metal halide, sulfate, phosphate, nitrate, acetate, carbonate hydrates, etc. ${ }^{[46,47]}$

However, during the phase change process, almost every hydrated salt material will undergo supercooling and phase separation. Therefore, many studies have focused on improving the performance of hydrated salt, reducing the degree of supercooling and phase separation to achieve better application prospects. ${ }^{[48-50]}$ However, the supercooling cannot be eliminated, and the supercooling can only be reduced as much as possible to make it crystallizes in the required temperature range in time.

\subsubsection{Molten salts}

Molten salt is generally called a molten liquid of inorganic salt and is a medium-to-high temperature phase change medium. The molten salt used as PCM mainly includes chloride, nitrate, carbonate, sulfate, etc. Molten salt has many advantages, such as: variety, low cost, low corrosion, high heat transfer, good liquidity, a wide range of use, and so on. However, pure molten salt has problems such as leakage, low thermal conductivity, etc., so it is usually modified to improve its performance. Both single molten salts and eutectic molten salts are investigated.

To overcome the weakenss of low thermal conductivity and other thermal performance problems of eutectic molten salt, adding filler is a common and effective method. EG is a suitable choice as an additive. It can improve the thermal conductivity of PCM, prevent liquid PCM from leaking, and resist corrosion. ${ }^{[51]}$ Graphite ${ }^{[52]}$ and $\mathrm{CuO}^{[53]}$ can also be used as additives to improve the thermal performance of hightemperature $\mathrm{PCM}$. For example, adding $\mathrm{CuO}$ nanoparticles into $\mathrm{KNO}_{3}$ and $\mathrm{NaNO}_{3}$ can improve thermal diffusivity and thermal conductivity. ${ }^{[54]}$

The corrosion of molten salt used as PCM is a main concern for the application of PCM. Liu et al. ${ }^{[5]}$ studied the corrosion behavior of $\mathrm{NaClNa}_{2} \mathrm{CO}_{3}$ (mass ratio: 40.55:59.45) eutectic salt on 316 stainless steel (SS316) vessels before and after 1000 thermal cycles. Studies have shown that the corrosion rate of SS316 increases almost linearly with the increase in the number of cycles, and the corrosion rate remains constant until the number of cycles is 350 .

\subsubsection{Metallic and alloy PCMs}

Metals and alloys have some characteristics, including high thermal conductivity, high latent heat per unit volume, relatively low vapor pressure, low latent heat per unit mass, low specific heat capacity, and so on. ${ }^{[56]}$ The most significant advantage of metal is high thermal conductivity, which leads to the high energy efficiency of the thermal energy storage system. ${ }^{[57]}$ Therefore, PCM usually does not require additional processing to improve thermal conductivity, thereby reducing the cost of PCM. However, encapsulating metal PCM is very important due to the activity and corrosiveness of metals. Metal can be used as PCM, including $\mathrm{Cu}, \mathrm{Al}, \mathrm{Mg}, \mathrm{Zn}, \mathrm{Si}$, etc., and its phase transition temperature is between $300{ }^{\circ} \mathrm{C}$ and $160{ }^{\circ} \mathrm{C}$. The higher melting temperature enables metals to be used for higher temperature latent heat storage. In addition, their alloys are also good choices for PCM, such as AlSi alloys, $\mathrm{CuSi}$ alloys, MgAlZn alloys, etc., among which Si has the effect of controlling the volume change of PCM during phase transformation.

However, metals and alloys are expensive, and the latent heat of metal per unit weight is relatively low, which can easily cause the heat storage equipment to be too heavy. They are reactive with other materials such as iron-based materials at high temperatures, so it is imperative to find suitable materials as containers with good compatibility with metals. ${ }^{[58,59]} \mathrm{Xu}$ et $a l .^{[60]}$ used an optimized hybrid sintering method to manufacture shape- stable PCM, in which Al was used as PCM and $\mathrm{Al}_{2} \mathrm{O}_{3}$ was used as support material. Under proper molding pressure and time, composite PCM has a higher thermal conductivity, higher density, and no leakage. AlSi alloy as PCM has become one of the alloys that have been widely studied due to its high latent heat capacity and excellent thermal reliability. Nomura et al. ${ }^{[13]}$ used $\alpha-\mathrm{Al}_{2} \mathrm{O}_{3}$ as the shell and $\mathrm{Al}-25 \mathrm{wt} \% \mathrm{Si}$ as the PCM and prepared microencapsulated PCM through two methods: boehmite coating and heatoxidation treatment. After 300 cycles in the temperature range of $500{ }^{\circ} \mathrm{C}$ to $650{ }^{\circ} \mathrm{C}$, the shell did not crack, and the phase transition properties remained almost constant, indicating that the shell had excellent durability.

\subsubsection{Eutectic PCMs}

Eutectic is the minimum melting composition of two or more components, each component will be completely melted and frozen, and there is no separation. Eutectic PCM is a combination of two or more compounds of organic, inorganic, or both. For thermal energy storage systems, a considerable amount of eutectic can be customized to almost any desired melting point. The main problem with these compounds is that the cost is twice or three times that of organic or inorganic compounds. ${ }^{[61-63]}$ Sari et al. studied the latent heat storage properties of organic co-crystals of certain fatty acids and glycerol. ${ }^{[64]}$ After 1000 thermal cycles, the synthesized fatty acid PCM remained good thermal stability in terms of thermal performance. No significant degradation was observed in the ester's chemical structure, demonstrating that the synthesized PCM has good thermal stability in long service life.

Most inorganic eutectic crystals are made of salt hydrates, and a small part is metal eutectic crystals. Eutectic molten salt is a new material that mixes two or more molten salts and has the characteristics of melting and solidification without material separation. ${ }^{[65]}$ Besides, eutectic salts are favored in applications due to their stable performance. ${ }^{[66,67]}$ 


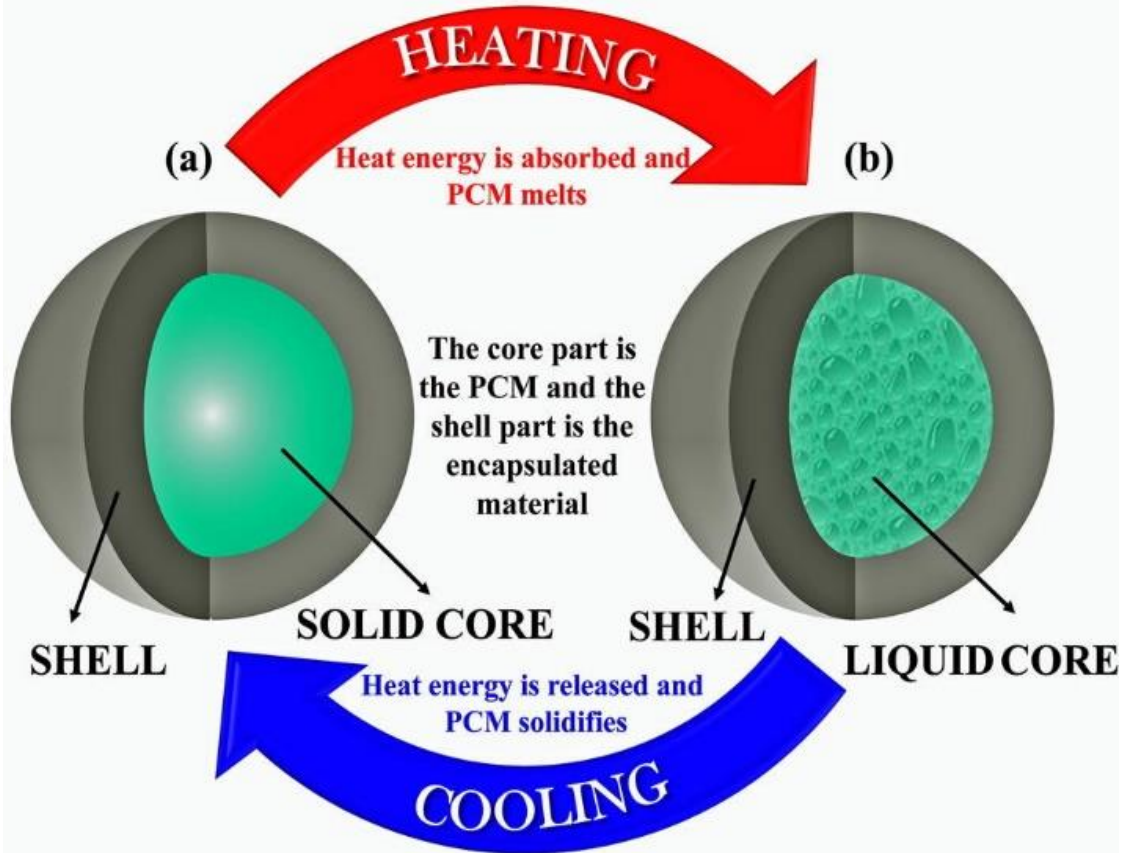

Fig. 3 Working principle of the encapsulated PCMs. (Reproduced with the permission form [1], Copyright, 2018 Elsevier Ltd.)

The eutectic containing organic and inorganic parts is called organic-inorganic composite eutectic. ${ }^{[68,69]}$ Alkan et al. ${ }^{[70]}$ studied the thermal properties of ethylene glycol distearate (EGDS) synthesized by the direct esterification reaction of ethylene glycol and SA. Compared with paraffin-based and fatty acid-based PCMs, EGDS has the advantages of greater energy storage capacity per unit mass, less odor, and less corrosiveness.

\subsection{Storage method of phase change materials}

To reduce the reactivity of PCM with the external environment, decrease the evaporation and diffusion rate, and make the processing procedures less energy demading, many research groups have developed noval storage methods. This section will discuss these methods.

\subsubsection{Encapsulation}

Encapsulation technology provides an opportunity to manufacture advanced PCMs with a larger heat transfer area, reduced reactivity with the external environment, and controlled volume changes during phase change. For these reasons, microencapsulated phase change materials (MEPCM) have attracted considerable attention for more than 20 years. ${ }^{[71,72]}$

Fig. 3 presents the working principle of encapsulated PCM. ${ }^{[1]}$ The core part is a PCM, and the shell part represents the encapsulation material. After heating, the PCM is melted while the shell remains solid, as shown in Fig. 3a. The PCM remains constant temperature and stores a certain amount of thermal energy during the melting process/phase change process, as shown in Fig. 3b. When cooled below the melting point, the PCM returns to its original solid state by releasing the absorbed heat (Fig. 3a).
The main parameters of the encapsulation are the thickness of the coating material, the encapsulation size, the thickness of the shell, and the geometry of the encapsulation. ${ }^{[73]}$

In PCM encapsulation technology, according to the final diameter of the capsule, encapsulation can be divided into three types: nanoencapsulation $(<1 \mu \mathrm{m})$; microencapsulation ( $1 \mu \mathrm{m}$ to $1 \mathrm{~mm})$; macroencapsulation $(1 \mathrm{~mm}$ to $1 \mathrm{~cm}$ ).

According to the encapsulation method, both organic and inorganic PCM can be classified into four categories: physicomechanical, chemical, physical, and physical-chemistry. ${ }^{[74,75]}$ In physico-mechanical methods, the capsule wall is mechanically applied or condensed around the capsule core, and moderate-sized capsules, for example, microcapsules, are obtained. Capsules prepared by chemical methods are smaller and have more heat capacity. Physico-mechanical methods include spray drying, centrifugal extrusion, vibrational nozzle, and solvent evaporation. Chemical processes include in situ polymerization, interfacial polycondensation, suspension polymerization, and emulsion Polymerization. ${ }^{[76]}$ The physical method retains the original chemical composition of the shell material formed through physical processes such as dehydration and adhesion. The most common physical method for microcapsule synthesis is electrospray. The physicochemical approach, including gelation and coacervation, leads to a solid and stable particle. There are three methods within this category, sol-gel, coacervation, and ionic gelation processes.

\subsubsection{Shape stabilized PCMs}

Microencapsulation of PCMs caused some problems awaiting solution, such as cost to encapsulate the PCM, leakage of the melted PCM when a capsule shell was damaged, and heat resistance caused by a capsule shell. 
The shape-stable PCM (SSPCM) is a new type of wrapped PCM. Its primary production method is to embed a PCM into a frame material in a porous structure or 3D network structure, also known as a form-stable phase change material (FSPCM). The mentioned frame materials are called support materials, which can restrict the flow of PCM to prevent leakage. In the past ten years, they have attracted great interest due to their excellent shape retention ability even after a large number of thermal cycles without any encapsulation. ${ }^{[77,78]}$ The shapestable PCM has several notable features, such as large heat capacity in the phase transition temperature region, suitable thermal conductivity, maintaining shape stability, and preventing leakage during the entire phase transition process. Proper selection of support materials can achieve higher PCM quality. Commonly used support materials are polymers and porous materials. ${ }^{[79]}$

Polymer-based SSPCM is usually manufactured by melt blending and casting molding methods. Polyethylene (PE) ${ }_{[}^{[80]}$ polypropylene (PP) ${ }^{[81]}$ epoxy resin, ${ }^{[82]}$ polyurethane (PU), ${ }^{[83}$ polyvinyl chloride (PVC), ${ }^{[84]}$ polylactic acid (PLA) ${ }^{[85]}$ are commonly used polymeric frame material. Electrospinning technology to manufacture $\mathrm{PCM} /$ polymer composite superfine fibers has recently become a new method for preparing shape-stable PCM. Polyethylene terephthalate (PET) and polyamide 6 are good materials for preparing PCM by electrospinning. Due to the good stability of composite fibers, fiber composite materials based on electrospinning technology have certain application prospects as phase change materials with stable shapes. ${ }^{[86]}$

In the porous materials-based SSPCM, the PCM can be absorbed in the porous structure of the porous material due to the absorption effect, resulting in a shape-stable PCM. The latent heat storage capacity of porous material-based SSPCM depends on the mass fraction of PCM absorbed in the support material. ${ }^{\left[{ }^{[7]}\right.}$ The higher the mass fraction of PCM in the support matrix, the greater the latent heat storage capacity. High porosity can ensure sufficient PCM adsorption and maintain high energy storage density. Expanded graphite, clay, metal foam, biomass-material, and other materials are commonly used support materials due to their rich pore structure. ${ }^{[88-91]}$ In the latest research, carbon scaffold, and metal-organic frameworks (MOFs), have been developed as porous supports to hold the molten liquid PCMs. ${ }^{\text {[92-94] }}$

The shape stability solves the PCM leakage problem. It has good thermal stability, reliability, low thermal conductivity, large latent heat, and is not flammable. Direct impregnation method (DIM) and vacuum adsorption method (VAM) are commonly used to prepare FSPCM of porous material microporous structure. ${ }^{[74]}$ In direct impregnation, the mixing of PCM and support material can be done in two ways. First, the PCM can be heated to a molten state and then mixed with the support material. Secondly, PCM can be mixed with a solid form of support material and then heated to a molten state. In VAM, besides the surface tension and capillary force of the porous material, the environmental pressure difference also contributes to the adsorption of liquid PCM.

Clay minerals have the advantages of low price and a wide range of sources. They have the characteristics of high porosity, large surface area, and medium pore size $(0.1$ to $100 \mu \mathrm{m})$. They are ideal support materials for the preparation of SSPCM, such as diatomite, ${ }^{[20]}$ kaolin, ${ }^{[95]}$ montmorillonite, ${ }^{[96]}$ sepiolite, ${ }^{[97]}$ vermiculite, ${ }^{[98]}$ and expanded perlite, ${ }^{[99]}$ etc.

Porous silica is a porous material with good adsorption and chemical stability. The three-dimensional network structure of porous silica can effectively prevent the leakage and flow of PCMs during the phase change process, ${ }^{[100]}$ so the porous silica-based composite phase change material has ideal thermal properties. ${ }^{[101]}$

Bio-based porous materials have also been widely used in the field of phase change energy storage in recent years, including wood, cotton, fruits, vegetables, and other plants. ${ }^{[102-}$ ${ }^{105]}$ This type of material is porous and environmental friendly and has a high phase change enthalpy. Thus bio-based PCM materials broaden the application range of PCMs in the field of biomedicine.

\subsubsection{Foam formation}

Polyurethane (PU) foams have been widely applied for thermal insulation as the ultimate energy savers. Polyurethane (PU) foams have high mechanical and chemical stability at both high and low temperatures, do not contain chlorofluorocarbons, and are recyclable. In order to incorporate PCM into the polyurethane foam structure, three methods are generally followed. They are: (i) injecting and dispersing PCM directly into PU foam; (ii) trapping PCM in the composite structure during the synthesis of PU foam; (iii) chemical grafting or preventing copolymerization of PCM (such as PEG). Preparation of a polyurethane block copolymer structure composed of PCM and PU. ${ }^{[106,107]}$ Sarier ${ }^{[108]}$ tested the direct incorporation of PEG600, PEG1000, and PEG1500 and their mixtures into PU foams, which are commercially used as insulating materials. Their results show that PU foams with different PEG components and contents exhibit different thermal properties and are suitable for different application scenarios, such as temperature regulation in mild and hot environments to prevent discontinuity when the external temperature suddenly rises or falls.

\subsection{Properties of PCMs}

The various properties of materials, such as physical, thermal, chemical, and kinetic properties, as well as cost, wide availability, non-toxic, adaptability, and stability, are considered the critical selection parameters for PCMs in any particular TES application. ${ }^{56]}$

Among all the characteristics of PCMs, the thermophysical properties are regarded as game-changers. Thus it is essential to determine its thermophysical properties to evaluate the suitability of a specific PCM in a particular application and temperature range. The most common method used to analyze the thermal properties (i.e., melting point and latent melting 
heat) of PCM is differential scanning calorimetry (DSC). In thermal performance, it is one of the critical requirements to select the PCM phase transition temperature to fall within the operating temperature range in a specific TES application. Other preferred thermal characteristics used to ensure the best performance of PCM include ideal latent heat, higher thermal conductivity, energy density, and heat capacity. ${ }^{[14]}$ The values of latent heat and heat capacity are related to the energy that the PCM can store or release. ${ }^{[109]}$ The higher thermal conductivity can ensure faster thermal energy storage and release in PCM. ${ }^{[110]}$ Furthermore, the successful utilization of latent heat energy storage systems largely depends on the thermal reliability and stability of the PCM. Therefore, for the long-term performance of the latent heat storage unit, it is always desirable to ensure the thermal stability of the PCM. The essential physical properties of an ideal PCM also include small volume change during the phase change, low vapor pressure within the operating temperature range, the advantage of phase equilibrium, the equivalent melting of the constituent components, and the required density. ${ }^{[56]}$ In addition to the technical aspects of PCM-based TES, its environmental and social impacts are also considered part of the evaluation criteria.

\section{Applications of PCMs}

Compared with sensible thermal storage, latent thermal storage based on PCM has a higher energy storage density, smaller system size, and lighter weight per unit of storage capacity. Therefore, it is widely used in solar energy utilization, waste heat recovery, building energy saving, thermal management systems, and civil and medical fields.

\subsection{Thermal utilization of solar energy}

PCM has high heat capacity, repeatability, and constant temperature characteristics in the phase change process. It has been widely used in thermal utilization of solar energy, such as solar water heating, solar photovoltaic, and solar lighting. ${ }^{[111-113]}$ For the application of TES in concentrated solar power (CSP) systems, various PCMs have been studied including organic compounds, molten salts, and metal alloys. Fig. 4 shows the latent enthalpy of different types of PCM at different temperatures. ${ }^{[113]}$ PCMs based on molten salt are usually cheap and have a high heat storage density, but they corrode containers, pipes, and valves.

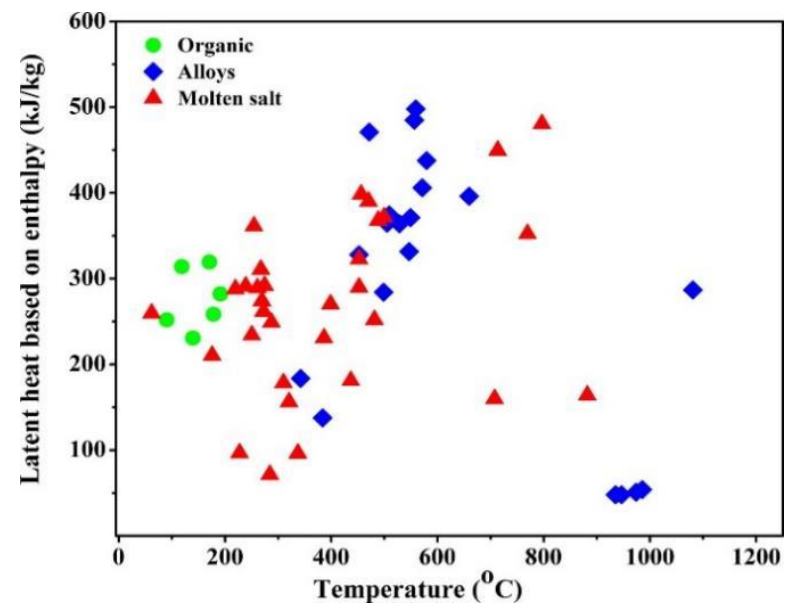

Fig. 4 Relationship between melting temperature and latent heat of PCMs. (Reproduced with the permission form [113], Copyright, 2016 John Wiley \& Sons, Ltd.)

\subsubsection{Solar power generation}

The purpose of developing solar power is to reduce the burden of household electricity consumption and protect the environment by using renewable clean energy. Concentrated solar power (CSP) is one of the most important applications of solar energy. It is well known that intermittence is the defect of solar energy in the application, which can be solved by a thermal energy storage (TES) system with high-temperature PCM because it can store heat on sunny days, release heat on rainy days or night. ${ }^{[114]}$ It is found that the value of overall energy efficiency without PCM is approximately $10 \%$. In comparison, the value of overall energy efficiency reaches to $30 \%$ after integrated with PCM, indicating that PCMs can improve the performance of solar power plants. ${ }^{[115]}$ The CSP plant with a TES system is shown in Fig. 5. ${ }^{[114]}$
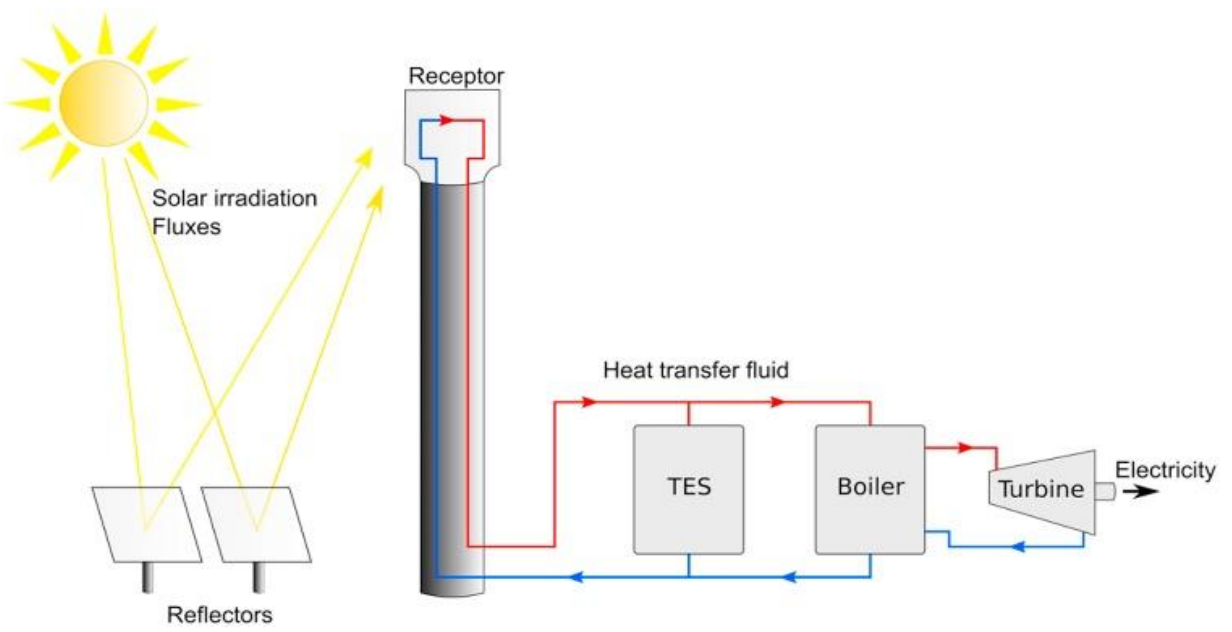

Fig. 5 CSP plant with a TES system. (Reproduced with the permission form [114], Copyright, 2018 Elsevier Ltd.) 
Zhao et al. ${ }^{[116]}$ developed a high-temperature latent heat storage system for solar power generation. $\mathrm{MgCl}_{2}$ with a melting temperature of $714^{\circ} \mathrm{C}$ was used as PCM, and graphite foam was used as an additive to improve thermal conductivity and energy efficiency. The simulation results show that the thermal conductivity of the graphite foam system is high. The graphite foam increases the system's return energy efficiency from $68 \%$ to $97 \%$, reduces the number of heat transfer fluid pipes by eight times, and dramatically reduces the cost. Heat pipes and heat sink fins can also improve the heat transfer and energy efficiency of the CSP's potential thermal energy storage. ${ }^{[117]}$ Besides, the system can be further optimized by using a cascaded PCM system. ${ }^{[118]}$

\subsubsection{Solar water heating system}

Solar water heating system is one of the most popular solar thermal systems. A single solar water heater can reduce ca. 50 tons of carbon dioxide emissions within 20 years. However, traditional solar water heating systems have problems such as poor solar energy collection, large heat loss at night, and low efficiency in cold climates, limiting the application of solar water heating systems. ${ }^{[119]}$ Therefore, the combination of PCM with large heat storage capacity and solar water heating system is a feasible and effective method to improve the performance of solar water heating systems. This method can not only enhance the efficiency of solar water heating system, but also has the advantages of low water temperature fluctuation. ${ }^{[120,121]}$

At present, there are three leading technologies for integrating PCM into solar water heating systems: integrating PCM into water storage containers, integrating PCM into solar collectors, and integrating PCM units into solar water heating loops. ${ }^{[122]}$ Varol et al. ${ }^{[123]}$ prepared a solar collector with PCM $\left(\mathrm{Na}_{2} \mathrm{CO}_{3} \cdot 10 \mathrm{H}_{2} \mathrm{O}\right)$ to obtain hot water from solar energy in cold weather. The experimental results confirm that PCM is very beneficial for improving the heat collection efficiency and useful energy of solar collectors. The helpful energy of solar collectors without PCM increases until noon and then begins to decrease, while solar collectors with PCM can absorb a

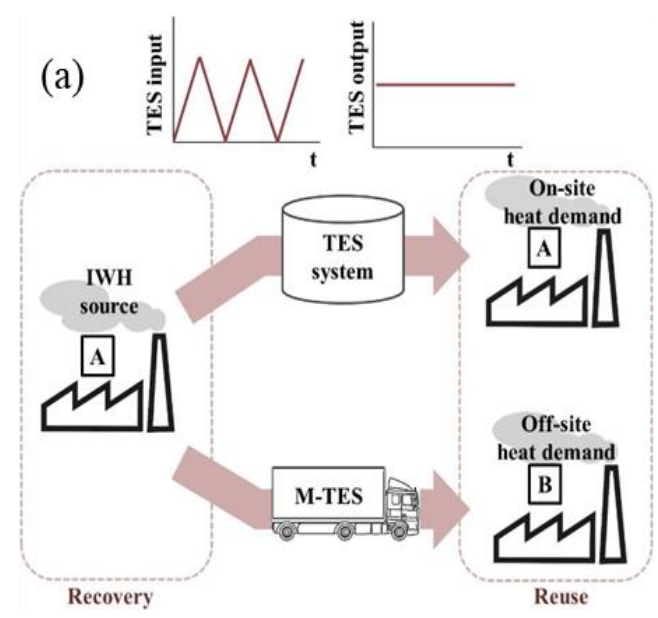

large amount of usable energy during the day to heat water after sunset. K1lıçkap et al. ${ }^{[124]}$ used calcium chloride hexahydrate as a PCM combined with a hot water collector. Their test results show that collectors with PCM are more efficient in different seasons and can provide hot water at an appropriate temperature of $1-1.5 \mathrm{~h}$ at night.

\subsection{Waste heat recovery}

Due to global warming and environmental issues, the demand for energy-saving technologies has increased, directly leading to the enormous interest in studying heat recovery systems. The waste heat recovery system not only saves energy, but also reduces heat loss instead of generating heat. ${ }^{[125]}$ The heat recovery rate in the exhaust gas reaches $60-95 \%$, which makes the energy efficiency of the building significantly improved. ${ }^{[126]}$

Moreover, industrial production emits a large amount of waste heat, mostly the metal and mineral processing industries that generate high-temperature waste heat, which have better reuse potential. ${ }^{[127]}$ Industrial heat recovery and reuse are essential to reduce carbon dioxide emissions and energy consumption. Due to the technical and financial difficulties of traditional heat recovery methods and the time and geographic mismatch between heat release and heat demand, these can be solved by PCM-based latent heat storage system. A typical heat recovery system for building and industrial waste heat is shown in Fig. $6 .^{[128,129]}$ Heat recovery devices can also be used for passive ventilation and mechanical ventilation. ${ }^{[130]}$

Magro et al ${ }^{[131]}$ proposed a steam generator integrated with high-temperature PCM to recover waste heat from the steel industry. The simulation results show that the steam generator and turbine size is reduced by ca. $41 \%$ compared with the traditional design, and the power generation is increased by $22 \%$. Therefore, PCM has a stabilizing effect on the steam parameters at the turbine inlet, thereby improving the overall efficiency. Nomura et al..$^{[132]}$ introduced the practicality of thermal energy storage systems with PCM. The function of thermal energy storage is to recover waste heat with a

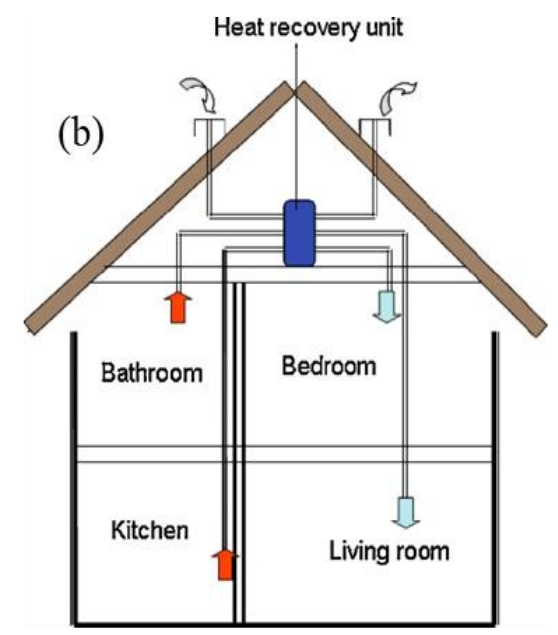

Fig. 6 Schematic diagram of on-site and off-site reuse of industrial waste heat (a) and a typical building heat recovery system (b). (Reproduced with the permission form [128, 129], Copyright, 2016 and 2012 Elsevier Ltd.) 
temperature higher than $300{ }^{\circ} \mathrm{C}$ from the steel plant and then send it to the chemical plant. The results show that the heat storage density of the latent heat storage system using $\mathrm{NaOH}$ as PCM is 2.76 times that of the sensible heat storage system. Besides, energy requirements, energy losses, and $\mathrm{CO}_{2}$ emissions are much lower than traditional systems, demonstrating the potential and feasibility of latent heat stored in the heat recovery in the industry.

Currently, the thermal energy recovery system based on PCMs has been widely regarded as one of the most promising methods to reduce fuel consumption. Because of its potential in harvesting wasted energy and reducing greenhouse gas emission, it should attract worldwide attention.

\subsection{Building energy conservation}

The increasing demand for thermal comfort in buildings has led to a corresponding increase in building energy consumption. ${ }^{[133]}$ Due to the cost of fossil fuels and environmental concerns, TES using PCM for heating and cooling buildings is becoming more and more popular. In extremely cold or extremely hot regions, electricity consumption varies significantly during the day and night, partly because of the changing demand for heating or cooling in the home. Therefore, improving the thermal insulation and energy efficiency of buildings is necessary to reduce the energy consumption of buildings. PCM can minimize demanded changes, so researchers have launched extensive research. ${ }^{[134,135]}$

PCM is mainly used in the field of building energy conservation by integrating PCM into buildings to increase the thermal inertia of buildings with the same mass. ${ }^{[49,136]}$ Recently, most researchers have been committed to embedding PCM into concrete and gypsum board commonly used in buildings to enhance the thermal and sound insulation performance of walls. ${ }^{[137,138]}$ In buildings, PCM can be integrated into envelopes, such as walls, roofs, and floors. ${ }^{[139-141]} \mathrm{Fu}$ et al. ${ }^{[142]}$ prepared expanded perlite (EP) $/ \mathrm{CaCl}_{2} \cdot 6 \mathrm{H}_{2} \mathrm{O}$ composites, in which EP can adsorb 55 wt $\% \mathrm{CaCl}_{2} \cdot 6 \mathrm{H}_{2} \mathrm{O}$. The composite PCM is then embedded into bricks to form PCM bricks and compared with commercial foam insulation bricks. The results show that PCM brick has two advantages, one is to reduce the maximum temperature of the room, and the other is to delay the temperature rise.

Among all the building envelope surfaces in the equatorial region, the roof bears the most considerable solar heat load. Solar energy heat from the roof accounts for a large amount of the building heat load. ${ }^{[143]}$ Therefore, the purpose of integrating PCM into the roof structure is to absorb the incoming energy through the melting process before the roof reaches the indoor space and reduce the heat absorption during peak energy demand via using higher melting latent heat, thereby improving indoor heat comfortable conditions and reduce cooling energy requirements. ${ }^{[144]}$ PCM can also be embedded in the roof, ${ }^{[145]}$ or it can be made into a multilayer structure with the roof. ${ }^{[146]}$ Some scholars have also introduced a scheme of combining the roof with a solar energy system, ${ }^{[147]}$ as well as photovoltaic roof technology ${ }^{[148]}$ to improve the suitability and the energy performance of buildings. PCM concrete is made and used in floors, ${ }^{[149]}$ where heat energy is stored in a mixture of concrete and PCM through indoor air and released at night. The purpose is to reduce the demand for heat energy for conventional heating in the house. It is reported that the application of PCM in concrete floor reduces the maximum floor temperature by $16 \pm 2 \%$ and increases the minimum temperature by $7 \pm 3 \%$.

Moreover, PCM can also be used for building equipment optimization. PCM integrated into building equipment can improve indoor thermal comfort by adjusting air temperature and improve the energy efficiency of air cooling, heating, and ventilation systems. ${ }^{[150,151]}$

However, special design considerations are necessary to promote the effectiveness of PCM, especially in the ventilation of the building. After melting/freezing cycles, some organic PCM (such as fatty acids) will cause a pungent smell. Besides, special safety measures should be considered when incorporating PCM into buildings because organic materials may catch fire under favorable conditions. ${ }^{[152]}$

\subsection{Thermal management system}

\subsubsection{Electronics heat sinks}

Technological advances in electronic devices have enhanced functions and reduced dimensions, and increased power density of packages. Therefore, thermal management is becoming increasingly crucial for the successful design of electronic devices such as cellular phones, notebook computers, tablet computers, and digital cameras. PCM-based heat sinks can keep the temperature of electronic equipment below a critical level to improve electronic equipment functionality. ${ }^{[153,154]}$

Yin et al. ${ }^{[155]}$ prepared rapid thermal response composite PCM by incorporating paraffin wax into expanded graphite and applied it to the electronic equipment radiator. It is found that the prepared PCM can effectively improve the performance of resisting high heat flux impact and Ensure higher reliability and operational stability. As a result, the apparent heat transfer coefficient of the experimental heat sink with PCM is three times higher than that of the heat sink without PCM. Krishna et al. ${ }^{[156]}$ added $\mathrm{Al}_{2} \mathrm{O}_{3}$ to trichloroethane to prepare nano-enhanced PCM and observed that the heat pipe's temperature dropped by more than $25 \%$, while the energy provided to the heat pipe was reduced by $30 \%$.

The thermal management system of electronic equipment integrated with PCM can reduce the power consumption of the radiator, the size of the cooling system, and the temperature of the system, which is very promising in improving the heat dissipation of electronic equipment. However, the main obstacle is the leakage of PCM in the surrounding medium, which is a safety issue. Therefore, it is necessary to focus on the shape stability of the PCM and the prevention of leakage. 


\subsubsection{Battery thermal management system}

In recent years, the demand for high-energy-density lithiumion batteries (LIB) used in portable electronic devices, batterypowered tools, and electric vehicles has proliferated. The main obstacles in using these batteries are safety, cost associated with cycle and calendar life, and performance. These are related to the thermal effects of the battery. The heat dissipation rate of the battery pack must be fast enough so that the battery pack never reaches the thermal runaway temperature. On the other hand, the more significant power requirements and increased energy density of lithium-ion battery packs result in higher operating temperatures. Most commercial LIB chemicals tend to degrade or age at temperatures of $60^{\circ} \mathrm{C}$ or above, which will result in rapid loss of content in subsequent charge/discharge cycles and a decrease in total power output. In order to solve these problems, a large amount of research has been conducted on active and passive thermal management systems of batteries for many applications that use LIB. The thermal management system relies on the transfer of heat from the surface of the battery to inhibit the rise in core temperature and prevent material degradation. PCM is often used to alleviate the considerable temperature rise during the discharge and charging process, thereby alleviating the performance degradation during the battery life and improving the safety of the battery system. ${ }^{[157]}$

Babapoor et al ${ }^{[158]}$ added carbon fiber to PCM to enhance its heat transfer potential. The maximum temperature increase in the battery simulator can be reduced by up to $45 \%$. Besides, carbon fiber will affect the temperature distribution in the battery. PCM composites containing a higher percentage of carbon fibers have a more uniform temperature distribution.

The PCM developed by Zhong et al. ${ }^{[159]}$ can control the maximum temperature below $45{ }^{\circ} \mathrm{C}$ and limit the temperature difference within $5{ }^{\circ} \mathrm{C}$. Furthermore, the heat sinks arranged on both sides of the module can effectively dissipate the heat stored in the PCM, thereby preventing thermal saturation of the PCM. The PCM cooling/resistance wire preheating coupling system can prevent the temperature from becoming too high and quickly preheat the battery at low temperatures.

When an internal short circuit occurs, a single battery or even a failure may trigger the battery thermal runaway, resulting in a local temperature rise to $180{ }^{\circ} \mathrm{C} \cdot{ }^{[160]} \mathrm{In}$ sharp contrast, by using PCM-based cooling, the temperature of the module remains within the normal operating range, and thermal runaway does not occur. The high thermal conductivity of PCM plays an essential factor in achieving uniform temperature distribution to improve the consistency of battery performance. ${ }^{[161]}$ Pan et al. ${ }^{[162]}$ prepared copper fiber/paraffin composite phase change material (CPCM) based on solid-state sintering technology. The results show that the copper fiber/paraffin CPCM can effectively improve the heat transfer performance and temperature uniformity of the battery within $2{ }^{\circ} \mathrm{C}$. Appropriately increasing the content of copper fiber is beneficial to obtain high heat transfer performance of the material. It is predicted that a copper fiber sintered skeleton with a porosity of $90 \%$ can provide the best performance composite material.

The PCM can effectively manage the temperature of the lithium-ion battery pack. At present, passive thermal management can be performed on batteries for stationary applications. For portable batteries, the device's safety, size, and relative weight are the most critical limiting factors and require further research.

\subsection{Applications in the civil fields \\ 3.5.1 Domestic hot water systems}

In most residential and commercial applications, such as bathing, laundry, and cleaning equipment, the required hot water temperature is about $50{ }^{\circ} \mathrm{C}$ to $60{ }^{\circ} \mathrm{C}$, and this range is considered ideal for PCM melting. Using PCM as the storage tank material can control the maximum temperature of the stored hot water and increase its heat storage capacity. ${ }^{[163]}$

Cabeza et al. ${ }^{[164]}$ studied a layered hot water storage tank containing a PCM module composed of several cylinders. A granular PCM-graphite composite material is used as PCM. The experimental results show that immersing the PCM module in a domestic hot water tank can provide a longer hot water time even without an external energy supply. Nkwetta et $a l .^{[165]}$ numerically analyzed the performance of domestic hot water tanks combined with PCM. It is found that as the amount of PCM increases, the stored energy increases. Studies have also shown that sodium acetate trihydrate with $10 \%$ graphite has higher storage potential and lower charging time.

\subsubsection{Thermal regulating textiles}

In recent years, there has been more research on applying phase change materials to textiles and clothing. When the ambient temperature or the temperature of the human body rises, the PCM incorporated into the textile tends to absorb heat and undergo a phase change, eventually storing latent heat. Once the ambient temperature or human body temperature begins to drop, the heat stored in the PCM fibers will be released. The heat storage and temperature regulation characteristics of PCM are very suitable for industrial applications in the textile field, such as sportswear and protective clothing. ${ }^{[166-168]}$

For apparel applications, a suitable PCM is a PCM with a phase change in the temperature range of 18 to $35^{\circ} \mathrm{C}$. Paraffin waxes, especially n-eicosane and n-hexadecane, are most preferred for textiles due to their high latent heat, phase transition temperature interval, and chemical inertness, nontoxic, non-corrosive, and non-hygroscopic. ${ }^{[169]}$ Besides, some eutectic $\mathrm{PCMs}^{\left[{ }^{[170]}\right.}$ have also been designed for application in textiles. Iqbal et al. ${ }^{[171]}$ reported the development of temperature-regulating fiber blended with microencapsulated PCM and found that the latent heat of polypropylene fiber blended with PCM was $9.2 \mathrm{~J} / \mathrm{g}$. This fiber can be used as smart textiles in curtains, high-altitude clothing, furniture, and car interiors. Zhao et al. ${ }^{[172]}$ prepared microencapsulated PCM 
with n-octadecane as the core and natural silk fibroin as the shell. It is reported that its latent heat is $88 \mathrm{~J} / \mathrm{g}$, which indicates that the new material is a promising choice for temperature regulating textiles.

\subsection{Application in the medical field}

PCM is also considered a promising material for different biomedical applications that require thermal protection, such as special bandages or dressings for burn wounds. Various PCMs used in the biomedicine field have been reported, such as microencapsulated PCMs used for thermal protection of tissues around tumors during cryosurgery and transportation and drug storage. ${ }^{[173,174]}$ Temperature-regulated textiles can keep the skin temperature within the desired range, making it useful as a bandage and for burn and heat/cool therapy. ${ }^{[175]}$

Mondieig et al. ${ }^{[176]}$ described application examples of molecular alloys for thermal protection of biomedical products during transportation or storage, especially the thermal protection of blood elements. Lv et al ${ }^{[177]}$ proposed that the healthy tissue surrounding cancer tumors can be thermally protected using microcapsule PCM during cryosurgery. These PCMs with massive latent heat and low thermal conductivity can absorb energy through latent heat, thereby protecting healthy tissues. Theoretical results prove that the proposed method can destroy cancer cells to the greatest extent within limited space while minimizing the freezing damage of surrounding healthy tissues. In another biomedical research, Wang ${ }^{[178]}$ introduced an innovative thermal biosensing technology that uses phase-change nanoparticles functionalized with RNA aptamers as thermal probes for susceptible and selective detection of thrombin. ${ }^{[178]}$

\subsection{Other fields}

PCM an also be applied in food field, such as storing, processing, and packaging food. ${ }^{[179]}$ The research of $\mathrm{Lu}^{[180]}$ shows that integrating supermarket display cabinets with PCM can cool food evenly. Johnston et al. ${ }^{[181]}$ reported that nanostructured calcium silicate PCM is a candidate material to provide heat buffering for food packaging.

PCM can also be used in thermal management of automobile engines, for example, to control internal combustion engine emissions and passive temperature management of electric vehicles ${ }^{[182]}$ Gumus et al. ${ }^{[183]}$ prepard a TES device based on $\mathrm{Na}_{2} \mathrm{SO}_{4} \cdot 10 \mathrm{H}_{2} \mathrm{O}$ as PCM for preheating internal combustion engines and observed a $17.4{ }^{\circ} \mathrm{C}$ increase in engine temperature in less than 10 minutes. Javani et al..$^{[184]}$ developed a latent heat TES system based on a mixture of nanoparticles and PCM for passive thermal management of electric vehicles. By adding carbon nanotubes to the PCM, the thermal characteristics of the storage medium are improved, thereby reducing the number of copper tubes in the TES device.

\section{Conclusions and outlook}

The latent heat storage system has apparent advantages over sensible heat storage, including smaller mass and volume, higher storage density, and lower energy loss to the surrounding environment, thus making PCMs viable in various application fields. The widely used phase change media are organic materials, inorganic materials, and eutectic materials. The organic PCMs with a high phase change heat capacity, chemical stability, non-corrosive, and reproducible thermal behavior after extensive thermal cycling are promising low-temperature phase change material. Inorganic PCMs have a higher energy density, thermal conductivity, and higher melting temperature but are more corrosive and exhibit a supercooling. Researchers are currently focusing on the form-stable organic composite PCMs.

High-efficiency PCMs are increasingly being applied in various areas, such as solar energy utilization, waste heat recovery, building energy conservation, thermal management systems, textiles, and medicine. Although the current latent heat TES based on PCM is one of the most promising applications in many fields, there are still tremendous work that need to be done. For example, encapsulation technology and nanomaterial additives should be developed to increase the specific heat and thermal conductivity of PCM, thereby enhancing the heat transfer performance of PCM. Add nucleating agent and thickener to reduce the degree of subcooling. The research of novel advanced PCM materials, especially environmentally friendly PCMs for energy storage, requires an in-depth investigation of the interaction mechanism between nanomaterials, support materials, and phase change media. Furthermore, it is necessary to continuously study how PCM meets the emerging requirements in different application fields.

\section{Acknowledgments}

We acknowledge the support by the National Natural Science Foundation of China (Grant No. 52003111 and U20A20340), National Key R\&D Program of China (2020YFB0408100), the Program for Guangdong Introducing Innovative and Entrepreneurial Team (2016ZT06C412), the Opening Project of Key Laboratory of Polymer Processing Engineering (South China University of Technology), Ministry of Education, (Grant No. KFKT2001), the Guangdong Basic and Applied Basic Research Foundation (Grant No. 2019A1515110982), GDAS' Project of Science and Technology Development (2020GDASYL-20200120028) and the Starting Research Fund Project of Xiangtan University (Grant No. 19QDZ15).

\section{Supporting Information}

Not Applicable.

\section{Conflict of Interest}

There is no conflict of interest.

\section{References}

[1] H. Nazir, M. Batool, F. J. Bolivar Osorio, M. Isaza-Ruiz, X. $\mathrm{Xu}, \mathrm{K}$. Vignarooban, P. Phelan, Inamuddin, A.M. Kannan, Inter. J. Heat Mass Transf., 2019, 129, 491-523, doi: 
10.1016/j.jheatmasstransfer.2018.09.126.

[2] Y. Zhang, L. Deng, H. Lv, G. Chen, npj Flex. Electro., 2020, 26, 1-7, doi: 10.1038/s41528-020-00089-2.

[3] W. Deng, L. Deng, Z. Li, Y. Zhang, G. Chen, ACS Appl. Mater. Interfaces, 2021, 13, 12131-12140, doi: 10.1021/acsami.1c01059. [4] Y. Zhang, Q. Zhang, G. Chen, Carbon Energy, 2020, 2, 408 436, doi: $10.1002 /$ cey2.68.

[5] X. Lu, J. Huang, W. Wong, J. Qu, Solar Energy Mater. Solar Cells, 2019, 200, 109987, doi: 10.1016/j.solmat.2019.109987.

[6] A. Gil, M. Medrano, I. Martorell, A. Lázaro, P. Dolado, B. Zalba, L.F. Cabeza, Renew. Sust. Energ. Rev., 2010, 14, 31-55, doi: 10.1016/j.rser.2009.07.035.

[7] K. Lim, J. Che, J. Lee, Appl. Therm. Eng., 2017, 110, 80-88, doi: 10.1016/j.applthermaleng.2016.08.098.

[8] N. Yu, R. Z. Wang, L.W. Wang, Prog. Energ. Combust., 2013, 39, 489-514, doi: 10.1016/j.pecs.2013.05.004.

[9] P. Pardo, A. Deydier, Z. Anxionnaz-Minvielle, S. Rougé, M. Cabassud, P. Cognet, Renew. Sust. Energ. Rev., 2014, 32, 591-610, doi: 10.1016/j.rser.2013.12.014.

[10] H. Mehling, Investigation of the options for thermal energy storage from the viewpoint of the energy form, 2015.

[11] L. Scapino, H.A. Zondag, J. Van Bael, J. Diriken, C.C.M. Rindt, Appl. Energy, 2017, 190, 920-948, doi: 10.1016/j.apenergy.2016.12.148.

[12] M.F. Demirbas Energ. Source. Part B, 2006, 1, 85-95, doi: 10.1080/009083190881481.

[13] T. Nomura, N. Sheng, C. Zhu, G. Saito, D. Hanzaki, T. Hiraki, T. Akiyama, Appl. Energy, 2017, 188, 9-18, doi: 10.1016/j.apenergy.2016.11.025.

[14] S.A. Mohamed, F.A. Al-Sulaiman, N.I. Ibrahim, M.H. Zahir, A. Al-Ahmed, R. Saidur, B.S. Yılbaş, A.Z. Sahin, A review on current status and challenges of inorganic phase change materials for thermal energy storage systems, Renew. Sust. Energ. Rev., 2017, 1072-1089, doi: 10.1016/j.rser.2016.12.012.

[15] G. Alva, Y. Lin, G. Fang, Energy, 2018, 144, 341-378, doi: 10.1016/j.energy.2017.12.037.

[16] E. Wilhelm, C. Richter, B.E. Rapp, Sensor. Actuat. A-Phys., 2018, 271, 303-347, doi: 10.1016/j.sna.2018.01.043.

[17] R. Gulfam, P. Zhang, Z. Meng, Appl. Energy, 2019, 238, 582-611, doi: 10.1016/j.apenergy.2019.01.114.

[18] S. Mondal, Appl. Therm. Eng., 28, 2008, 1536-1550, doi: 10.1016/j.applthermaleng.2007.08.009.

[19] I. Sarbu, C. Sebarchievici, Sustainability, 2018, 10, 191, doi: 10.3390/su10010191.

[20] J. Huang, B. Wu, S. Lyu, T. Li, H. Han, D. Li, J.-K. Wang, J. Zhang, X. Lu, D. Sun, Sol. Energ. Mat. Sol. C., 2021, 219, 110797, doi: 10.1016/j.solmat.2020.110797.

[21] M. Liu, W. Saman, F. Bruno, Solar Energ. Mat. Solar C., 2012, 16, 2118-2132, doi: 10.1016/j.rser.2012.01.020.

[22] Y. Zhang, H. Liu, J. Niu, X. Wang, D. Wu, Appl. Energy, 2020, 264, 114729, doi: 10.1016/j.apenergy.2020.114729.

[23] X. Du, H. Wang, X. Cheng, Z. Du, RSC Adv., 2016, 6, 4264342648, doi: 10.1016/j.tca.2017.02.012.

[24] M.M. Kenisarin, Renew. Sust. Energy Rev., 2010, 14, 955970, doi: 10.1016/j.rser.2009.11.011.
[25] H. Nazir, M. Batool, M. Ali, A.M. Kannan, Appl. Therm.

Eng., 2018, 142, 466-475, doi: 10.1016/j.applthermaleng.2018.07.025.

[26] A. Sar1, Energ. Convers. Manage., 2004, 45, 2033-2042, doi: 10.1016/j.enconman.2003.10.022.

[27] K. Kaygusuz, A. Sari, Energ. Source. Part A, 2007, 29, 261270, doi: $10.1080 / 009083190957568$.

[28] M. Akgün, O. Aydın, K. Kaygusuz, Energ. Convers. Manage., 2007, 48, 669-678, doi: 10.1016/j.enconman.2006.05.014.

[29] S. Himran, A. Suwono, G.A. Mansoori, Energ. Source., 1994, 16, 117-128, doi: 10.1080/00908319408909065.

[30] P. Zhang, X. Xiao, Z.W. Ma, Appl. Energy, 2016, 165, 472510, doi: 10.1016/j.apenergy.2015.12.043.

[31] K. Pielichowski, K. Flejtuch, J. Pielichowski, Polymer, 2004, 45, 1235-1242, doi: 10.1016/j.polymer.2003.12.045.

[32] K. Pielichowski, K. Flejtuch, Polym. Advan. Technol., 2002, 13, 690-696, doi: 10.1002/pat.276.

[33] Y. Zhou, X. Liu, D. Sheng, C. Lin, F. Ji, L. Dong, S. Xu, H. Wu, Y. Yang, Chem. Eng. J., 2018, 338, 117-125, doi: 10.1016/j.cej.2018.01.021.

[34] F. Wang, X. Fang, Z. Zhang, Sol. Energ. Mat. Sol. C., 2018, 176, 381-390, doi: 10.1016/j.solmat.2017.10.025.

[35] B. Wu, S. Lyu, H. Han, T. Li, H. Sun, J.-K. Wang, D. Li, F. Lei, J. Huang, D. Sun, Compos. Part B, 2021, 205, 108500, doi: 10.1016/j.compositesb.2020.108500.

[36] H.-C. Zhang, B.-h. Kang, X. Sheng, X. Lu, Polymers, 2019, 11, doi: 10.3390/polym11122043.

[37] B. Liang, X. Lu, R. Li, W. Tu, Z. Yang, T. Yuan, Sol. Energ. Mat. Sol. C., 2019, 200, 110037, doi: 10.1016/j.solmat.2019.110037.

[38] D. Rozanna, T.G. Chuah, A. Salmiah, T.S.Y. Choong, M. Sa'ari, Inter. J. Green Energy, 2005, 1, 495-513, doi: 10.1081/ge-200038722.

[39] F.O. Cedeño, M.a.M. Prieto, A. Espina, J.R. García, Thermochim. Acta, 2011, 369, 39-50, doi: 10.1016/s00406031(00)00752-8.

[40] A. Sar1, A. Karaipekli, Mater. Chem. Phys., 2008, 109, 459464, doi: 10.1016/j.matchemphys.2007.12.016.

[41] A. Sarı, A. Karaipekli, C. Alkan, Chem. Eng. J., 2009, 155, 899-904, doi: 10.1016/j.cej.2009.09.005.

[42] D. Chandra, R. Chellappa, W.-M. Chien, J. Physics Chem. Solids, 2005, 66, 235-240, doi: 10.1016/j.jpcs.2004.08.047.

[43] T. Bo, T. Zhi-Cheng, L. Rui-Bin, M. Chang-Gong, Z. JingNan, Energ. Convers. Manage., 2010, 51, 1905-1910, doi: 10.1016/j.enconman.2010.02.021.

[44] Q. Yan, C. Liang, Sol. Energy, 2008, 82, 656-662, doi: 10.1016/j.solener.2007.12.008.

[45] X. Wang, E. Lu, W. Lin, C. Wang, Energ. Convers. Manage., 2000, 41, 135-144, doi: 10.1016/s0196-8904(99)00096-5.

[46] M. Kenisarin, K. Mahkamov, Sol. Energ. Mat. Sol. C., 2016, 145, 255-286, doi: 10.1016/j.solmat.2015.10.029.

[47] Y. Lin, G. Alva, G. Fang, Energy, 2018, 165, 685-708, doi: 10.1016/j.energy.2018.09.128. 
[48] M. Fashandi, S.N. Leung, Sol. Energ. Mat. Sol. C., 2018, 178 259-265, doi: 10.1016/j.solmat.2018.01.037.

[49] K. Yuan, Y. Zhou, W. Sun, X. Fang, Z. Zhang, Composit. Sci. Techno., 2018, 156, 78-86, doi: 10.1016/j.compscitech.2017.12.021.

[50] X. Li, Y. Zhou, H. Nian, F. Zhu, X. Ren, O. Dong, C. Hai, Y. Shen, J. Zeng, Appl. Therm. Eng., 2016, 102, 708-715, doi: 10.1016/j.applthermaleng.2016.04.029.

[51] L. Zhong, X. Zhang, Y. Luan, G. Wang, Y. Feng, D. Feng, Sol. Energy, 2014, 107, 63-73, doi: 10.1016/j.solener.2014.05.019.

[52] H. Tian, W. Wang, J. Ding, X. Wei, M. Song, J. Yang, Appl. Energy, 2015, 148, 87-92, doi: 10.1016/j.apenergy.2015.03.020. [53] Y. Luo, X. Du, A. Awad, D. Wen, Inter. J. Heat Mass Transf., 2017, $\quad \mathbf{1 0 4}$ 658-664,

10.1016/j.ijheatmasstransfer.2016.09.004.

[54] P. D. Myers, T.E. Alam, R. Kamal, D.Y. Goswami, E. Stefanakos, Appl. Energy, 2016, 165, 225-233, doi: 10.1016/j.apenergy.2015.11.045.

[55] M. Liu, S. Bell, M. Segarra, N.H. Steven Tay, G. Will, W. Saman, F. Bruno, Sol. Energ. Mat. Sol. C., 2017, 170, 1-7, doi: 10.1016/j.solmat.2017.05.047.

[56] A. Sharma, V.V. Tyagi, C.R. Chen, D. Buddhi, Renew. Sustain. Energy Rev., 2009, 13, 318-345, doi: 10.1016/j.rser.2007.10.005.

[57] C.E. Andraka, A.M. Kruizenga, B.A. Hernandez-Sanchez, E.N. Coker, Energy Procedia, 2015, 69, 726-736, doi: 10.1016/j.egypro.2015.03.083.

[58] A.I. Fernández, C. Barreneche, M. Belusko, M. Segarra, F. Bruno, L.F. Cabeza, Sol. Energ. Mat. Sol. C., 2017, 171, 275-281, doi: 10.1016/j.solmat.2017.06.054.

[59] N. Gokon, S. Nakamura, T. Yamaguchi, T. Kodama, Energy Procedia, 2015, 69, 1759-1769, doi: 10.1016/j.egypro.2015.03.145.

[60] Y. Xu, Y.-L. He, G.-H. Zhu, S. Lv, B. Shan, Energy Procedia, 2017, 105, 4328-4333, doi: 10.1016/j.egypro.2017.03.907.

[61] D. Wei, S. Han, X. Shen, J. Chem. Thermodynam., 2016, 101, 7-11, doi: 10.1016/j.jct.2016.05.008.

[62] P. Gallart-Sirvent, M. Martín, G. Villorbina, M. Balcells, A. Solé, C. Barrenche, L.F. Cabeza, R. Canela-Garayoa, RSC Adv. 2017, 7, 24133-24139, doi: 10.1039/c7ra03845c.

[63] R.K. Sharma, P. Ganesan, V.V. Tyagi, J. Thermal Analys. Calorime., 2016, 124, 1357-1366, doi: 10.1007/s10973-0165281-5.

[64] A. Sarı, A. Biçer, A. Karaipekli, C. Alkan, A. Karadag, Synthesis, Sol. Energ. Mat. Sol. C., 2010, 94, 1711-1715, doi: 10.1016/j.solmat.2010.05.033.

[65] X. Huang, G. Alva, Y. Jia, G. Fang, Renew. Sustain. Energy Rev., 2017, 72, 128-145, doi: 10.1016/j.rser.2017.01.048.

[66] Z. Ge, F. Ye, H. Cao, G. Leng, Y. Qin, Y. Ding, Particuology, 15 (2014) 77-81, doi: 10.1016/j.partic.2013.09.002.

[67] E. Risueño, A. Faik, A. Gil, J. Rodríguez-Aseguinolaza, M. Tello, B. D'Aguanno, J. Alloy. Compound., 2017, 705, 714-721, doi: 10.1016/j.jallcom.2017.02.173.
[68] A. Karaipekli, A. Sarı, A. Biçer, Appl. Therm. Eng., 2016 107, 55-62, doi: 10.1016/j.applthermaleng.2016.06.160.

[69] S.N. Gunasekara, V. Martin, J.N. Chiu, Renew. Sustain. Energy Rev., 2017, 73, 558-581, doi: 10.1016/j.rser.2017.01.108. [70] C. Alkan, K. Kaya, A. Sar1, Mater. Lett., 2008, 62, 1122-1125, doi: 10.1016/j.matlet.2007.07.061.

[71] M. Delgado, A. Lázaro, J. Mazo, B. Zalba, Renew. Sustain. Energy Rev., 2012, 16, 253-273, doi: 10.1016/j.rser.2011.07.152v. [72] W. Hu, X. Yu, Renew. Energ., 2014, 62, 454-458, doi: 10.1016/j.renene.2013.07.047.

[73] Y.E. Milián, A. Gutiérrez, M. Grágeda, S. Ushak, Renew. Sustain. Energy Rev., 2017, 73, 983-999, doi: 10.1016/j.rser.2017.01.159.

[74] R. Jacob, F. Bruno, Renew. Sustain. Energy Rev., 2015, 48, 79-87, doi: 10.1016/j.rser.2015.03.038

[75] P.B. Salunkhe, P.S. Shembekar, Renew. Sustain. Energy Rev., 2012, 16, 5603-5616, doi: 10.1016/j.rser.2012.05.037.

[76] G. Alva, Y. Lin, L. Liu, G. Fang, Energ. Buildgs., 2017, 144, 276-294, doi: 10.1016/j.enbuild.2017.03.063.

[77] G. Zhou, J. He, Appl. Energy, 2015, 138, 648-660, doi: 10.1016/j.apenergy.2014.10.058.

[78] N. Zhang, Y. Yuan, Y. Yuan, T. Li, X. Cao, Energ. Buildgs., 2014, 82, 505-511, doi: 10.1016/j.enbuild.2014.07.049.

[79] N. Zhu, S. Li, P. Hu, S. Wei, R. Deng, F. Lei, Sustain. Cities and Soc., 2018, 43, 251-264, doi: 10.1016/j.scs.2018.08.028.

[80] P. Sobolciak, M. Karkri, M.A. Al-Maadeed, I. Krupa, Renew. Energ., 2016, 88, 372-382, doi: 10.1016/j.renene.2015.11.056.

[81] M.J. Mochane, A.S. Luyt, Thermochim. Acta, 2012, 544, 63 70, doi: 10.1016/j.tca.2012.06.017.

[82] Z. Wang, W. Situ, X. Li, G. Zhang, Z. Huang, W. Yuan, C. Yang, C. Yang, Appl. Therm. Eng., 2017, 123, 1006-1012, doi: 10.1016/j.applthermaleng.2017.05.179.

[83] W. Kong, X. Fu, Y. Yuan, Z. Liu, J. Lei, RSC Adv., 2017, 7, 29554-29562, doi: 10.1039/c7ra04504b.

[84] X. Jin, J. Li, P. Xue, M. Jia, Sol. Energ. Mat. Sol. C., 2014, 130, 435-441, doi: 10.1016/j.solmat.2014.07.013.

[85] X. Lu, J. Huang, B. Kang, T. Yuan, J.-p. Qu, Sol. Energ. Mat. Sol. C., 2019, 192, 170-178, doi: 10.1016/j.solmat.2018.12.036.

[86] C. Chen, L. Wang, Y. Huang, Appl. Energy, 2011, 88, 3133 3139, doi: 10.1016/j.apenergy.2011.02.026.

[87] T. Shi, X. Zhang, J. Qiao, X. Wu, G. Chen, G. Leng, F. Lin, X. Min, Z. Huang, Polymer, 2021, 212, 123143, doi: 10.1016/j.polymer.2020.123143.

[88] S. Wu, T.X. Li, T. Yan, Y.J. Dai, R.Z. Wang, Inter. J. Heat Mass Transf., 2016, 102, 733-744, doi: 10.1016/j.ijheatmasstransfer.2016.06.066.

[89] B. Tian, W. Yang, L. Luo, J. Wang, K. Zhang, J. Fan, J. Wu, T. Xing, Sol. Energy, 2016, 127, 48-55, doi: 10.1016/j.solener.2016.01.011.

[90] C. Wang, T. Lin, N. Li, H. Zheng, Renew. Energ., 2016, 96, 960-965, doi: 10.1016/j.renene.2016.04.039.

[91] Y. Zhao, C.Y. Zhao, Z.G. Xu, H.J. Xu, Inter. J. Heat Mass Transf., 2016, 99, 170-181, doi: 10.1016/j.ijheatmasstransfer.2016.03.076. 
[92] J. Tang, M. Yang, W. Dong, M. Yang, H. Zhang, S. Fan, J. Wang, L. Tan, G. Wang, RSC Adv., 2016, 6, 40106-40114, doi: 10.1039/c6ra04059d.

[93] J. Shen, P. Zhang, L. Song, J. Li, B. Ji, J. Li, L. Chen, Compos. Part B, 2019, 179, 107545, doi: 10.1016/j.compositesb.2019.107545.

[94] N. Hu, H. Li, Q. Wei, K. Zhou, W. Zhu, L. Zhang, S. Li, W. Ye, Z. Jiao, J. Luo, L. Ma, Q. Yan, C.-T. Lin, Compos. Part B, 2020, 200, 108293, doi: 10.1016/j.compositesb.2020.108293.

[95] A. Sar1, Energ. Buildings, 2015, 96, 193-200, doi: 10.1016/j.enbuild.2015.03.022.

[96] W. Xiaofeng, Y. Siyuan, W. Jincheng, Polymer Inter., 2017, 66, 1284-1294, doi: 10.1002/pi.5384.

[97] Q. Shen, J. Ouyang, Y. Zhang, H. Yang, Appl. Clay Sci., 2017, 146, 14-22, doi: 10.1016/j.clay.2017.05.035.

[98] X. Li, H. Wei, X. Lin, X. Xie, Sol. Energ. Mat. Sol. C., 2016, 155, 9-13, doi: 10.1016/j.solmat.2016.04.057.

[99] W. Zhang, X. Zhang, Z. Huang, Z. Yin, R. Wen, Y. Huang, X. Wu, X. Min, J. Mater. Sci. Tech., 2018, 34, 379-386, doi: 10.1016/j.jmst.2017.06.003.

[100] X. Wan, C. Chen, S. Tian, B. Guo, J. Energy Storage, 2020, 28, 101276, doi: 10.1016/j.est.2020.101276.

[101] Z. Chen, D. Su, M. Qin, G. Fang, Energ. Buildins., 2015, 86, 1-6, doi: 10.1016/j.enbuild.2014.10.013.

[102] W. Chao, H. Yang, G. Cao, X. Sun, X. Wang, C. Wang, Energy, 2020, 202, 117636, doi: 10.1016/j.energy.2020.117636. [103] D.G. Atinafu, S. J. Chang, S. Kim, J. Hazard. Mater., 2020, 399, 123041, doi: 10.1016/j.jhazmat.2020.123041.

[104] N. Sheng, R. Zhu, T. Nomura, Z. Rao, C. Zhu, Y. Aoki, H. Habazaki, T. Akiyama, Sol. Energ. Mat. Sol. C., 2020, 206, 110280, doi: 10.1016/j.solmat.2019.110280.

[105] Y. Xie, W. Li, H. Huang, D. Dong, X. Zhang, L. Zhang, Y. Chen, X. Sheng, X. Lu, ACS Sustain. Chem. Eng., 2020, 8, 84488457, doi: 10.1021/acssuschemeng.0c02959.

[106] N. Sarier, E. Onder, Thermochim. Acta, 2007, 454, 90-98, doi: 10.1016/j.tca.2006.12.024.

[107] M. You, X.-x. Zhang, X.-c. Wang, L. Zhang, W. Wen, Thermochim. Acta, 2010, 500, 69-75, doi: 10.1016/j.tca.2009.12.013.

[108] N. Sarier, E. Onder, Thermal insulation capability of PEGcontaining polyurethane foams, Thermochim. Acta, 2008, 475, 15-21, doi: 10.1016/j.tca.2008.06.006.

[109] P. Zhang, F. Ma, X. Xiao, Appl. Energy, 2016, 173, 255 271, doi: 10.1016/j.apenergy.2016.04.012.

[110] R.M. Al Ghossein, M.S. Hossain, J.M. Khodadadi, Inter. J. Heat Mass Transf., 2017, 107, 697-711, doi: 10.1016/j.ijheatmasstransfer.2016.11.059.

[111] M.Z. Jacobson, M.A. Delucchi, Energ. Policy, 2011, 39, 1154-1169, doi: 10.1016/j.enpol.2010.11.040.

[112] X. Zhang, X. Zhao, S. Smith, J. Xu, X. Yu, Renew. Sustain. Energy Rev., 2012, 16, 599-617, doi: 10.1016/j.rser.2011.08.026. [113] T. Nomura, T. Akiyama, Int. Energ. Res., 2018, 1207-1224, doi: 10.1002/er.3611.

[114] U. Pelay, L. Luo, Y. Fan, D. Stitou, M. Rood, Renew. Sustain. Energy Rev., 2017, 79, 82-100, doi: 10.1016/j.rser.2017.03.139.

[115] M.H. Mahfuz, A. Kamyar, O. Afshar, M. Sarraf, M.R. Anisur, M.A. Kibria, R. Saidur, I.H.S.C. Metselaar, Energ. Convers Manage, 2014, 78, 486-492, doi: 10.1016/j.enconman.2013.11.016.

[116] W. Zhao, D.M. France, W. Yu, T. Kim, D. Singh, Renew. Energ., 2014, 69, 134-146, doi: 10.1016/j.renene.2014.03.031.

[117] D.J. Malan, R.T. Dobson, F. Dinter, Energy Procedia, 2015, 69, 925-936, doi: 10.1016/j.egypro.2015.03.176.

[118] D. Singh, W. Zhao, W. Yu, D.M. France, T. Kim, Sol. Energy, 2015, 118, 232-242, doi: 10.1016/j.solener.2015.05.016. [119] Z. Wang, F. Qiu, W. Yang, X. Zhao, Renew. Sustain. Energy Rev., 2015, 52, 645-652, doi: 10.1016/j.rser.2015.07.184.

[120] A. Najafian, F. Haghighat, A. Moreau, Energ. Buildings, 2015, 106, 59-64, doi: 10.1016/j.enbuild.2015.05.036.

[121] M.H. Mahfuz, M.R. Anisur, M.A. Kibria, R. Saidur, I.H.S.C. Metselaar, Inter. Commu. Heat Mass Transf.,2014, 57, 132-139, doi: 10.1016/j.icheatmasstransfer.2014.07.022.

[122] S. Seddegh, X. Wang, A.D. Henderson, Z. Xing, Renew. Sustain. Energy Rev., 2015, 49, 517-533, doi: 10.1016/j.rser.2015.04.147.

[123] Y. Varol, A. Koca, H.F. Oztop, E. Avci, Expert Syst. Appl., 2010, 37, 2724-2732, doi: 10.1016/j.eswa.2009.08.007.

[124] S. Kılıçkap, E. El, C. Yıldız, Therm. Sci. Eng. Prog., 2018, 5, 25-31, doi: 10.1016/j.tsep.2017.10.016.

[125] K. Zhong, Y. Kang, Appl. Them. Eng., 2009, 29, 830-840, doi: 10.1016/j.applthermaleng.2008.04.003.

[126] C.A. Roulet, F.D. Heidt, F. Foradini, M.C. Pibiri, Energ. Buildings, 2001, 33, 495-502, doi: 10.1016/S03787788(00)00104-3.

[127] S. Brückner, S. Liu, L. Miró, M. Radspieler, L.F. Cabeza, E. Lävemann, Appl. Energy, 2015, 151, 157-167, doi: 10.1016/j.apenergy.2015.01.147.

[128] L. Miró, J. Gasia, L.F. Cabeza, Appl. Energy, 2016, 179, 284-301, doi: 10.1016/j.apenergy.2016.06.147.

[129] A. Mardiana-Idayu, S.B. Riffat, Renew. Sustain. Energy Rev., 2012, 16, 1241-1255, doi: 10.1016/j.rser.2011.09.026.

[130] Y.P. Zhou, J.Y. Wu, R.Z. Wang, Energ. Buildings, 2007. 39, 1202-1210, doi: 10.1016/j.enbuild.2006.12.010.

[131] F. Dal Magro, S. Savino, A. Meneghetti, G. Nardin, Energy, 2017, 137, 1107-1118, doi: 10.1016/j.energy.2017.04.051.

[132] T. Nomura, N. Okinaka, T. Akiyama, Conserv. Recycl., 2010, 54, 1000-1006, doi: 10.1016/j.resconrec.2010.02.007.

[133] V. V. Tyagi, S. C. Kaushik, S. K. Tyagi, T. Akiyama, Renew. Sustain. Energy Rev., 2011, 15, 1373-1391, doi: 10.1016/j.rser.2010.10.006.

[134] R. Zeinelabdein, S. Omer, G. Gan, Renew. Sustain. Energy Rev., 2018, 82, 2843-2868, doi: 10.1016/j.rser.2017.10.046.

[135] R. Ye, W. Lin, K. Yuan, X. Fang, Z. Zhang, Appl. Energy, 2017, 193, 325-335, doi: 10.1016/j.apenergy.2017.02.049.

[136] Y. Liu, M. Xie, X. Gao, Y. Yang, Y. Sang, Appl. Therm. Eng., 2018, 140, 112-119, doi: 10.1016/j.applthermaleng.2018.05.042.

[137] V. D. Cao, S. Pilehvar, C. Salas-Bringas, A.M. Szczotok, J.F. Rodriguez, M. Carmona, N. Al-Manasir, A.-L. Kjøniksen, Energ. Convers. Manage., 2017, 133, 56-66, doi: 
10.1016/j.enconman.2016.11.061.

[138] B.A. Young, Z. Wei, J. Rubalcava-Cruz, G. Falzone, A. Kumar, N. Neithalath, G. Sant, L. Pilon, Mater. Design, 2017, 126, 259-267, doi: 10.1016/j.matdes.2017.04.023.

[139] I. Mandilaras, M. Stamatiadou, D. Katsourinis, G. Zannis, M. Founti, Building Environ., 2013, 61, 93-103, doi: 10.1016/j.buildenv.2012.12.007.

[140] Y. Li, H. Lin, S.M.A.S. Hejazi, C. Zhao, M. Xie, Construct. Building Mater, 2017, 149, 272-278, doi: 10.1016/j.conbuildmat.2017.05.110.

[141] P. Saikia, A.S. Azad, D. Rakshit, Int. J. Therm. Sci., 2018, 126, 105-117, doi: 10.1016/j.ijthermalsci.2017.12.029.

[142] L. Fu, Q. Wang, R. Ye, X. Fang, Z. Zhang, Renew. Energ., 2017, 114, 733-743, doi: 10.1016/j.renene.2017.07.091.

[143] K.T. Zingre, E.-H. Yang, M.P. Wan, Energy, 2017, 133, 900-912, doi: 10.1016/j.energy.2017.05.181.

[144] J. Lei, K. Kumarasamy, K.T. Zingre, J. Yang, M.P. Wan, E.H. Yang, Appl. Energ., 2017, 190, 57-63, doi: 10.1016/j.apenergy.2016.12.114.

[145] H.J. Alqallaf, E.M. Alawadhi, Energ. Buildings, 2013, 61, 73-80, doi: 10.1016/j.enbuild.2013.01.041.

[146] K.T. Zingre, M.P. Wan, S.K. Wong, W.B.T. Toh, I.Y.L. Lee, Energy, 2015, 82, 813-826, doi: 10.1016/j.energy.2015.01.092.

[147] W. Saman, F. Bruno, E. Halawa, Sol. Energy, 2005, 78, 341 349, doi: 10.1016/j.solener.2004.08.017.

[148] W. Lin, Z. Ma, M.I. Sohel, P. Cooper, Energ. Convers. Manage, 2014, $\mathbf{8 8}, \quad 218-230, \quad$ doi: 10.1016/j.enconman.2014.08.019.

[149] A.G. Entrop, H.J.H. Brouwers, A.H.M.E. Reinders, Sol. Energy, 2011, 85, 1007-1020, doi: 10.1016/j.solener.2011.02.017. [150] H. Benli, A. Durmuş, Performance analysis of a latent heat storage system with phase change material for new designed solar collectors in greenhouse heating, Sol. Energy, 2009, 83, 21092119, doi: 10.1016/j.solener.2009.07.005.

[151] M. Song, F. Niu, N. Mao, Y. Hu, S. Deng, Energ. Buildings, 2018, 158, 776-793, doi: 10.1016/j.enbuild.2017.10.066.

[152] S. Ramakrishnan, X. Wang, J. Sanjayan, J. Wilson, Appl. Energ., 2017, 194, 410-421, doi: 10.1016/j.apenergy.2016.04.084.

[153] A. Alrashdan, A.T. Mayyas, S. Al-Hallaj, J. Mater. Process. Techn., 2010, 210, 174-179, doi: 10.1016/j.jmatprotec.2009.07.011.

[154] L. Colla, D. Ercole, L. Fedele, S. Mancin, O. Manca, S. Bobbo, J. Heat Transf., 2017, 139, doi: 10.1115/1.4036017.

[155] H. Yin, X. Gao, J. Ding, Z. Zhang, Energ. Convers. Manage., 2008, 49, 1740-1746, doi: 10.1016/j.enconman.2007.10.022.

[156] J. Krishna, P.S. Kishore, A.B. Solomon, Exp. Therm. Fluid Sci., 2017, 81, 84-92, doi: 10.1016/j.expthermflusci.2016.10.014. [157] C.-V. Hémery, F. Pra, J.-F. Robin, P. Marty, J. Power Sources, 2014, 270, 349-358, doi: 10.1016/j.jpowsour.2014.07.147.

[158] A. Babapoor, M. Azizi, G. Karimi, Appl. Thermal Eng., 2015, 82, 281-290, doi: 10.1016/j.applthermaleng.2015.02.068.
[159] G. Zhong, G. Zhang, X. Yang, X. Li, Z. Wang, C. Yang, C. Yang, G. Gao, Appl. Therm. Eng., 2017, 127, 176-183, doi: 10.1016/j.applthermaleng.2017.08.022.

[160] R. Kizilel, R. Sabbah, J.R. Selman, S. Al-Hallaj, J. Power Sources, 2009, 194, 1105-1112, doi: 10.1016/j.jpowsour.2009.06.074.

[161] D. Zou, X. Ma, X. Liu, P. Zheng, Y. Hu, Inter. J. Heat Mass Transf., 2018, 120, 33-41, doi: 10.1016/j.ijheatmasstransfer.2017.12.024.

[162] M. Pan, W. Lai, Renew. Energ., 2017, 114, 408-422, doi: 10.1016/j.renene.2017.07.004.

[163] M.A. Fazilati, A.A. Alemrajabi, Energ. Convers. Manageme., 2013, 71, 138-145, doi: 10.1016/j.enconman.2013.03.034.

[164] L.F. Cabeza, M. Ibáñez, C. Solé, J. Roca, M. Nogués, Sol. Energ. Mat. Sol. C., 2006, 90, 1273-1282, doi: 10.1016/j.solmat.2005.08.002.

[165] D.N. Nkwetta, P.-E. Vouillamoz, F. Haghighat, M. ElMankibi, A. Moreau, A. Daoud, Appl. Therm. Eng., 2014, 67 460468, doi: 10.1016/j.applthermaleng.2014.03.051.

[166] N. Sarier, E. Onder, G. Ukuser, Thermochim. Acta, 2015, 613, 17-27, doi: 10.1016/j.tca.2015.05.015.

[167] M. Kamali Moghaddam, S.M. Mortazavi, J. Microencapsul., 2015, 32, 737-744, doi: 10.3109/02652048.2015.1073388.

[168] D. Sun, K. Iqbal, Cellulose, 2017, 24, 3525-3543, doi: 10.1007/s10570-017-1326-6.

[169] Y. Shin, K. Son, D.I. Yoo, Thermochim. Acta, 2010, 511, 17, doi: 10.1016/j.tca.2010.07.016.

[170] F. Salaün, G. Bedek, E. Devaux, D. Dupont, L. Gengembre, J. Membrane Sci., 2010, 370, 23-33, doi: 10.1016/j.memsci.2010.11.033.

[171] K. Iqbal, D. Sun, Renew. Energ., 2014, 71, 473-479, doi; 10.1016/j.renene.2014.05.063.

[172] L. Zhao, J. Luo, H. Wang, G. Song, G. Tang, Appl. Therm. Eng., 2016, 99, 495-501, doi: 10.1016/j.applthermaleng.2015.12.111.

[173] K. Pielichowska, K. Pielichowski, Prog. Mater. Sci., 2014, 65, 67-123, doi: 10.1016/j.pmatsci.2014.03.005.

[174] R. De Santis, V. Ambrogi, C. Carfagna, L. Ambrosio, L. Nicolais, J. Mater. Sci. Mater. Medic., 2006, 17, 1219-1226, doi: 10.1007/s10856-006-0595-7.

[175] X. Zhang, Woodhead Publishing Series in Textiles, 2001, 34-57, doi: 10.1533/9781855737600.34.

[176] D. Mondieig, F. Rajabalee, A. Laprie, H.A.J. Oonk, T. Calvet, M. Angel Cuevas-Diarte, Transfus. Apher. Sci., 2003, 28, 143-148, doi: 10.1016/s1473-0502(03)00016-8.

[177] Y. Lv, Y. Zou, L. Yang, Chem. Eng. Sci., 2011, 66, 39413953, doi: 10.1016/j.ces.2011.05.031.

[178] C. Wang, M. Hossain, L. Ma, Z. Ma, J.J. Hickman, M. Su, Biosens. Bioelectron., 2010, 26, 437-443, doi: 10.1016/j.bios.2010.07.097.

[179] S. Devahastin, S. Pitaksuriyarat, Appl. Therm. Eng., 2006, 26, 1705-1713, doi: 10.1016/j.applthermaleng.2005.11.007. 
[180] Y.L. Lu, W.H. Zhang, P. Yuan, M.D. Xue, Z.G. Qu, W.Q. Tao, Appl. Therm. Eng., 2010, 30, 85-91, doi: 10.1016/j.applthermaleng.2008.10.003.

[181] J.H. Johnston, J.E. Grindrod, M. Dodds, K. Schimitschek, Curr. Appl. Phys., 2008. 8, 508-511, doi: 10.1016/j.cap.2007.10.059.

[182] K.-b. Kim, K.-w. Choi, Y.-j. Kim, K.-h. Lee, K.-s. Lee, Energy, 2010, 35, 478-484, doi: 10.1016/j.energy.2009.10.015.

[183] M. Gumus, Appl. Therm. Eng., 2009, 29, 652-660, doi: 10.1016/j.applthermaleng.2008.03.044.

[184] N. Javani, I. Dincer, G.F. Naterer, J. Power Sources, 2014, 268, 718-727, doi: 10.1016/j.jpowsour.2014.06.107.

\section{Author information}

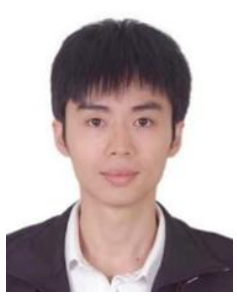

Jintao Huang obtained his bachelor degree in 2009 and master degree in 2012 from Sichuan University, and doctor degree in 2015 from South China University of Technology. Now, he is an associate professor in Guangdong University of Technology. His research focuses on the preparation and performance of bio-based energy materials and the preparation of energy storage materials by traditional processing methods.

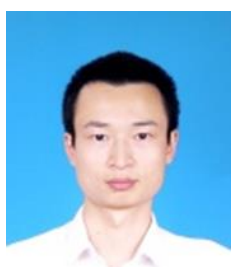

Yue luo, Lecturer, master advisors, School of Mechanical Engineering, Xiangtan University. He obtained his bachelor degree from Xiangtan University, and doctor degree from South China University of Technology with Prof. Jinping Qu. His research focuses on preparation and performance of energy

storage materials, advanced manufacturing technology of high-performance polymer composites.

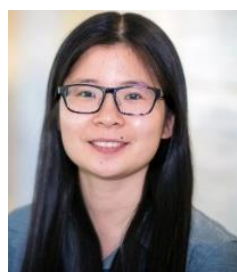

Jingfang $Y \boldsymbol{u}$ received her BS (2011) from Xiangtan University, her MS (2013) from Texas State University, and her PhD (2015) from University of Connecticut. She is currently working as a post-doctoral associate in the Department of Chemistry, University of Oxford.

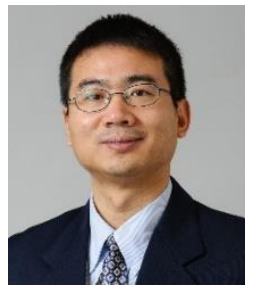

Luyi Sun received his B.S. from South China University of Technology in 1998 and Ph.D. from the University of Alabama in 2004. After his postdoctoral training at Texas A\&M University, he worked at TOTAL Petrochemicals USA, Inc. from 2006 to 2009. He was an assistant professor at Texas State University from 2009 to 2013. Dr. Sun joined the University of Connecticut as an associate professor in 2013 and was promoted to professor in 2018. His research focuses on the design and synthesis of nanostructured materials for various applications.

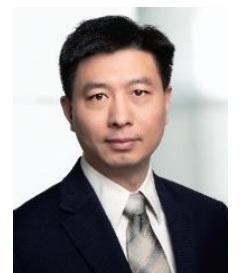

Hongbo Zeng is a Professor in the Department of Chemical and Materials Engineering at the University of Alberta, a Tier 1 Canada Research Chair in intermolecular forces and interfacial science, a Fellow of the Canadian Academy of Engineering and a Member of the Royal Society of Canada's College of New Scholars. He received his BSc and MSc at Tsinghua University, and obtained his PhD at University of California, Santa Barbara. His research interests are in colloid and interface science, functional materials, with a special focus on intermolecular and surface interactions in soft matter and engineering applications. He has published over 350 refereed research journal articles. His research has been recognized by many awards such as the CSChE Innovation Award of the Chemical Institute of Canada, International Award for Outstanding Young Chemical Engineer, and the NSERC Steacie Fellowship.

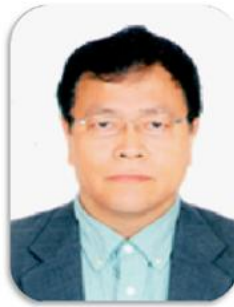

Yonggang Min obtained his Ph.D. from Professor Alan G. MacDiarmid at University of Pennsylvania in 1995, and then had worked various technical positions among several global fortune 500 companies and Universities. Now, he is a professor in Guangdong University of Technology. Professor Min had a strong academic training and industrial experience in carbon based materials, electric active polymers, and polymeric materials. He had published over 130 technical papers (citation over 3000), filed over 200 patents, and conducted about 100 technical presentations worldwide.

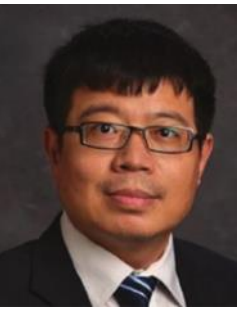

Zhanhu Guo, an Associate Professor in the Department of Chemical and Biomolecular Engineering, University of Tennessee, Knoxville, USA, obtained a Ph.D. degree in Chemical Engineering from Louisiana State University (2005) and received 3-year (2005-2008) postdoctoral training from the Mechanical and Aerospace Engineering Department at the University of California Los Angeles. Dr. Guo chaired the Composite Division of the American Institute of Chemical Engineers (AIChE, 2010-2011) and directs the Integrated Composites Laboratory. His current research focuses on multifunctional nanocomposites for education, transportation, safety, information, catalysis, energy harvesting and storage, electronics, and environmental remediation applications.

Publisher's Note Engineered Science Publisher remains neutral with regard to jurisdictional claims in published maps and institutional affiliations. 